\title{
UN JURISTA EN EL NACIMIENTO DE LA CIENCIA POLİTICA MODERNA: LOS ESTUDIOS DE LAS ORGANIZACIONES DE PARTIDO DE MOISEI OSTROGORSKI ${ }^{1}$
}

\section{A JURIST IN THE ORIGINS OF MODERN POLITICAL SCIENCE: MOISEI OSTROGORSKI'S STUDIES ON PARTY ORGANIZATIONS}

\author{
Pedro L. López Herraiz \\ Universidad Autónoma de Madrid
}

\begin{abstract}
SUMARIO: I. PLANTEAMIENTO: PROBLEMAS DE LA LECTURA POLITOLÓGICA DE OSTROGORSKI. II. APUNTES DE UNA BIOGRAFIA ENTRE EL DERECHO, LA POLIITICA Y LA CIENCIA POLÍTICA. III. LA IMPORTANCIA DE LAS "FUERZAS" POLÍTICAS EN DETRIMENTO DE LAS "FORMAS". 3.1. Los partidos políticos como ángulo muerto de los estudios jurídicos. 3.2. La "nueva ciencia política" de Ostrogorski: la observación de las "fuerzas" políticas. IV. APARENTES TENSIONES DISCIPLINARES: OSTROGORSKI COMO JURISTA. 4.1. La "frialdad" del jurista ante el movimiento por los derechos políticos de las mujeres. 4.2. Elementos jurídicos para la comprensión de las organizaciones de partido. 4.3. El moment 1900 de la ciencia jurídica francesa desde la perspectiva de sus lecturas de Ostrogorski. V. CONCLUSIONES.
\end{abstract}

Resumen: El trabajo de Moisei Ostrogorski sobre las organizaciones de partido en Estados Unidos e Inglaterra (1903) fue considerado por la ciencia política de la segunda mitad del siglo XX como fundacional de la disciplina. En este artículo se discute el carácter genealógico de esta lectura, exponiendo que Ostrogorski era, también, un jurista. Su biografia, su investigación sobre los derechos de las mujeres e, incluso, su trabajo más propiamente politológico sobre los partidos, nos muestran este carácter de Ostrogorski como jurista. Además, las lecturas de su obra por parte de los juristas franceses de su tiempo expresan los problemas de proyectar sobre el pasado las divisiones disciplinares del presente.

Abstract: Moisei Ostrogorski's work on North American and English party organizations (1903) has been considered as a landmark by political scientists in the second half of $20^{\text {th }}$ century and. This article discusses the genealogic character of such a approach, arguing that Ostrogorski was also a legal scholar. His biography, his research on women's rights and even his political science oriented work on parties, all show that the Russian author made use of legal tools. In addition, the readings of Ostrogorski's work by coetaneous French legal scholars, show the problems of looking to the past through the lens of current disciplinary divisions.

1 Este artículo se ha realizado en el marco del proyecto de investigación "Tradición y constitución: problemas constituyentes de la España contemporánea" DER2014-56291-C3-1-P, MINECO. Agradezco a Laura Beck, Héctor Dominguez, Ekaterina Eremina, Marta Llorente y Antonio Luque sus comentarios a este trabajo. 
Palabras clave: Moisei Ostrogorski, derecho constitucional, ciencia politica moderna, historia de las ciencias sociales, partidos politicos, juristas franceses.

Key Words: Moisei Ostrogorski, constitutional law, modern political science, social sciences history, political parties, French legal scholars.

\section{PLANTEAMIENTO: PROBLEMAS DE LA LECTURA POLITOLÓGICA DE OSTROGORSKI.}

Este trabajo pretende resituar a nivel disciplinar los estudios fundacionales sobre las organizaciones de partido de Moisei Ostrogorski ${ }^{2}$, subrayando el bagaje de jurista y constitucionalista de este autor de origen ruso e impronta francesa. Y es que, si el nombre de Ostrogorski sigue diciendo algo hoy en dia, lo hace, principalmente, en las facultades y en los departamentos universitarios de ciencia politica. En ello ha colaborado el rol que jugó la lectura de este pensador en un proceso que iba mucho más allá de su figura: el de la construcción por parte de la ciencia politica de una genealogía propia que ayudase a legitimar su exitosa extensión en el competido campo de los saberes sociales durante la segunda mitad del siglo XX, especialmente en el ámbito angloamericano. Esta ciencia política moderna de marcado acento empírico buscó en los estudios previos sobre partidos políticos y élites aparecidos en el paso del siglo XIX al XX sus pioneros y sus fundadores, algo natural -inevitable incluso- para una disciplina académica joven. De esta manera, los estudios sobre partidos políticos posteriores a la Segunda Guerra Mundial han venido citando de manera canónica las obras de autores como Robert Michels u Ostrogorski, a los que se ha identificado metodológicamente con las claves dominantes décadas después en la disciplina.

Para el caso de la entronización politológica de nuestro autor fue central la lectura llevada cabo por Seymour Martin Lipset en su estudio introductorio a una reedición de la gran obra de Ostrogorski, Democracy and the organization of political parties $^{3}$. Lipset, renombrado representante de la ciencia y la sociología política de la segunda posguerra, se centró en los caracteres de la obra de Ostrogorski que, incomunicados del resto de su perspectiva, mejor encajaban con el itinerario tomado posteriormente por los estudios políticos. Así, Lipset colocó al trabajo del pensador ruso la etiqueta de pionero de varios ismos de la ciencia politica: conductismo, funcionalismo o comparatismo. El traslado atemporal de estas etiquetas no es per se errado, pero puede ser problemático desde una perspectiva históricamente rigurosa, ya que proyecta sobre la ciencia del pasado las cuestiones que preocupan a la ciencia de hoy, devolviéndonos una imagen deformada de aquella, incapaz de reflejar sus motivaciones y su carácter.

2 La obra por la que es principalmente conocido es: Moisei Ostrogorski, La démocratie et l'organisation des partis politiques (2 vols.), Calmann-Lévy, París, 1903.

3 Seymour M. Lipset, "Introduction. Ostrogorski and the Analytical Approach to the Comparative Study of Political Parties", en Moisei Ostrogorski, Frederick Clarke (trad.) Democracy and the Organization of Political Parties. Vol. I: England, Quadrangle Books, Chicago, 1964 [1902], pp. ix-1xv. 
Esto último es precisamente lo que ocurre de manera muy acentuada en el caso que nos ocupa, como se desprende de una lectura más detenida y diversificada de los trabajos del pensador ruso y de un conocimiento más profundo de su trayectoria. Un simple acontecimiento de su biografia, hasta ahora desconocido, es clarificador respecto de la difícil determinación del carácter disciplinar de las investigaciones de Ostrogorski y de su cercanía al mundo del derecho: su candidatura en 1907 a la Académie des sciences morales et politiques francesa como correspondiente extranjero en la sección de Législation, Droit public et Jurisprudence. Si sabemos de este intento es por una correspondencia dirigida desde San Petersburgo y otros enclaves de Europa oriental al conocido antropólogo francés, Lucien Lévy-Bruhl, en la que Ostrogorski planeaba una serie de estrategias para movilizar los votos de los académicos franceses en su favor ${ }^{4}$. El pensador ruso tenía una relación de confidente amistad con Lévy-Bruhl, una de las cabezas más prominentes de la escuela sociológica durkheimiana, y parecía bien conectado con importantes figuras de la enseñanza superior francesa como el historiador Gabriel Monod, el economista Yves Guyot o el recién nombrado director de la École libre des sciences politiques (ELSP o École), Anatole Leroy-Beaulieu. Respecto de esta última institución, Ostrogorski pretendía, a través de su director, hacer un uso intensivo de su condición de antiguo alumno para ganarse el voto de los numerosos miembros de la Académie que se contaban entre su profesorado.

Esta inmersión en el campo académico francés quedaba subrayada con una proclama que difuminaba su adscripción nacional: "Soy un escritor occidental y sobre las cosas de occidente, no soy ruso más que por nacionalidad"5. Además, en sus cartas de 1907, Ostrogorski combinaba estas gestiones con el parte de las últimas novedades de su actividad politica en el campo del asociacionismo político judío como candidato para la segunda y tercera Dumas del Imperio Ruso. A este respecto, se mostraba como un pensador devenido en político que veía su nueva actividad con una mezcla de pasión y de encono. De hecho, no acababa de separar su candidatura a la Académie de la política rusa cuando afirmaba respecto del antiguo ocupante del sillón al que aspiraba Ostrogorski, el fallecido Konstantin Pobedonostzeff (caracterizado por Tolstoi en el marido de su Anna Karénina) lo siguiente: "yo percibo simplemente la belleza del espectáculo: un judio toma el asiento de un gran inquisidor, un hombre apasionado de la libertad sucede a uno de los más siniestros artífices del despotismo"6.

Entre sus títulos, Ostrogorski disponía de sus actividades legislativas como diputado y alto funcionario, sin embargo, consideraba que sus méritos eran principalmente académicos. Al referirse a estos últimos, su imagen como padre de la ciencia política despojada de elementos valorativos quedaba definitivamente desencajada. No nos encontraríamos solo ante un autor inmerso en el complejo campo de las ciencias sociales francesas de la época y comprometido políticamente, sino que también se proclamaba a sí mismo como un especialista,

\footnotetext{
4 Cartas de 24-3-1907, 6-4-1907, 28-4-1907, 23-5-1907, 27-7-1907, 5-11-1907 y 23-12-1907; Institut mémoires de l'édition contemporaine (Caen, Francia; IMEC en adelante), LVB7 dossier 5.

5 Carta de 6-4-1907, IMEC, LVB7 dossier 5. Todas las traducciones al español son propias.

6 Carta de Ostrogorski a Lévy-Bruhl de 24-3-1907, IMEC, LVB7 dossier 5.
} 
primero, en derecho público y, segundo, en ciencia política ${ }^{7}$, que además ponía sus esperanzas de ser elegido en Adhémar Esmein, uno de los principales iuspublicistas del rico moment 1900 de la ciencia jurídica francesa, que era, en su opinión, el mejor conocedor de su valía académica. En resumen, además de científico político, Ostrogorski participaba de distintos campos de las ciencias sociales de Francia, de la oposición al zarismo y se consideraba como un jurista que pretendía acceder a la sección más jurídica de la Académie. Tales méritos no serian suficientes para imponerse a su colega y compatriota, el sociólogo e historiador del derecho Maksim Kovalevsky ${ }^{8}$, del que confesaba con cierta suficiencia: "En cuanto a cantidad en materia publicada él tiene más títulos que yo, en cuanto a la calidad no es a mi a quien le corresponde juzgarlo..."

Estas desventuras de candidato nos valen para subrayar que Ostrogorski fue algo más que un pionero de la ciencia política, al punto de que ese "algo más" implica una discusión de su aceptada condición de pionero. Otras lecturas de su obra menos conocidas e intensivas nos hablan de un autor poliédrico en el aspecto ideológico y en el disciplinar. En lo ideológico, un pensador de corte liberal como él fue leído en su tiempo con especial júbilo -sobre todo en Franciapor aquellos que pretendian derribar el parlamentarismo desde posiciones derechistas (Charles Benoist, Augustin Cochin o Charles Maurras ${ }^{10}$ ) e izquierdistas (Édouard Berth o Charles Péguy o ${ }^{11}$ ). En lo disciplinar, historiadores del pensamiento político como Pierre Rosanvallon o Richard Bellamy han subrayado la faceta teórica de la obra del autor ruso, considerando que su valor radica en el análisis de la relación entre el sistema democrático y los partidos politicos de masas ${ }^{12}$. Aunque, si hay un tipo de lecturas que sirven para desmontar la acrítica inclusión de Ostrogorski en el canon de la ciencia política empírica, estas son las de los principales representantes de los estudios políticos que le eran contemporáneos. Bryce, Abbott L. Lowell o Graham Wallas no dudaron en oponerse a las pretensiones filosóficas, al tono apasionado y a las

7 Carta de 6-4-1907, IMEC, LVB7 dossier 5.

8 Para una introducción a su figura, véase Larissa Titarenko y Elene Zdravomyslova, Sociology in Russia. A Brief History, Palgrave Macmillan, Cham, 2017, pp. 21-26.

9 Carta de 6-4-1907, IMEC, LVB7 dossier 5.

10 Todos ellos en mayor o menor medida cercanos a la cada vez más importante organización de extrema derecha Action Française. Charles Benoist, "Le suffrage universel et l'évolution des partis politiques", Revue des deux mondes, vol. 20, 4, 1904, pp. 520-542; "Comment on capte le suffrage et le pouvoir. La "machine", Revue des deux mondes, vol. 21, 6, 1904, pp. 885-918; Augustin Cochin, Les sociétés de pensée et la démocratie. Études d'histoire révolutionnaire, Plon, París, 1921, pp. 233-282; Charles Maurras, "Un Avis au Lecteur", Feuilleton de la Gazette de France, 1-3-1903.

11 Cercanos, por lo general, al sindicalismo revolucionario que, en muchos casos, evolucionaría hacia posiciones nacionalistas e incluso hacia el fascismo: Édouard Berth "Politique et Socialisme", Le Mouvement Socialiste, vol. 6, 132, 1903, pp. 5-37; Charles Péguy, "Vient de paraître. La démocratie et l'organisation des partis politiques", Cahiers de la quinzaine, vol. 4, 12, 1903, pp. 29-60.

12 Richard Bellamy, "La sociedad de masas y el surgimiento de la teoría moderna de la democracia", en Terence Ball, Richard Bellamy (eds.), Historia del pensamiento politico en el siglo XX, Sandra Chaparro (trad.), Akal, Madrid, 2013 [2005], pp. 79-113; Pierre Rosanvallon, "Lire Ostrogorski", en Moisei Ostrogorski, La démocratie et les partis politiques, Seuil, París, 1979 [1912], pp. 8-21. 
propuestas constitucionales de la obra de Ostrogorski, comprendiendo mucho mejor la naturaleza de su método que lo que se desprende de las lecturas genealógicas posteriores. ${ }^{13}$

En las páginas que siguen no me centraré en estas otras lecturas de Ostrogorski, sino en su ligamiento -conflictivo, intermitente y contradictorio- con el espacio académico de los juristas que sirve, también, para discutir las lecturas uniformes y pacificadas en lo disciplinar de su obra. Esto no supone afirmar, cómo podría pensarse, que Ostrogorski era antes un jurista que un científico político. Lo interesante radica en como la compleja incardinación disciplinar de sus trabajos nos muestra un momento en el que los caracteres de la ciencia politica y del derecho público y sus fronteras respectivas no estaban definidos de la misma manera que lo están hoy. Para ello, comenzaré realizando, a partir de algunas fuentes novedosas, una presentación de su trayectoria vital, que es aún hoy demasiado desconocida. En ese recorrido prestaré especial atención a aquellas cuestiones que le emparentan con el mundo jurídico (epígrafe II). Después, expondré brevemente la evolución del fenómeno partidista antes del siglo XX y de las dificultades de los juristas para dar cuenta de él (3.1). Ostrogorski, como se verá, formó parte a finales del siglo XIX de un emergente movimiento disciplinar de científicos políticos que pretendía superar la incapacidad de los enfoques jurídicos para el estudio de lo que denominó, en su léxico, como las "fuerzas" políticas (3.2). Sin embargo, una lectura más detenida de su obra me permitirá mostrar que, a pesar de su distanciamiento de cierta manera de entender los estudios jurídicos, Ostrogorski era también un jurista. Esto se ve claramente en su trabajo sobre los derechos de las mujeres (4.1), pero también en sus estudios más propiamente politológicos sobre partidos (4.2) y en las lecturas que se hicieron de estos últimos por parte de los representantes de la ciencia jurídica francesa de su tiempo (4.3).

\section{APUNTES DE UNA BIOGRAFÍA ENTRE EL DERECHO, LA POLÍTICA Y LA CIENCIA POLÍTICA.}

En contraste con la proliferación de referencias a su trabajo, varios extremos de la vida de Ostrogorski siguen siendo, actualmente, bastante desconocidos, a pesar de los meritorios trabajos de Gaetano Quagliariello e Igor Andrev ${ }^{14}$. Esto se

13 James Bryce, "Preface", en Democracy and the Organization of Political Parties, Moisei Ostrogorski, Macmillan, Londres y Nueva York, 1902, pp. xxxix-xlvii; Abbott L. Lowell, "Review "Democracy and the Organization of Political Parties" by M. Ostrogorski, Frederick Clarke and James Bryce", The American Historical Review, vol. 8, 3, 1903, pp. 519-521; Graham Wallas, "The American Analogy", The Independent Review, vol. I, 2, 1903, pp. 505-516; Human Nature in Politics, Archibald constable, Londres, 1908, pp. 124-126.

${ }_{14} \mathrm{El}$ primero se centró en el paso, en aquel momento poco conocido, de Ostrogorski por la École libre des sciences politiques de París, en el proceso de elaboración de su libro y en su relación con académicos y editores angloamericanos como Bryce, George A. Macmillan o Wallas. Gaetano Quagliariello, Politics Without Parties. Moisei Ostrogorski and the Debate on Political Parties on the Eve of the Twentieth Century, Hugo Bowles (trad.), Averbury, Hants (Ing.) y Brookfield (VT), 1996 [1993]. El segundo, historiador ruso, ha investigado los archivos y fuentes de su país, aportando importantes elementos sobre su infancia, juventud y sobre su vuelta a Rusia a principios del siglo XX. Su trabajo más completo al respecto es Igor V. Andrev, M.Ya. Ostrogorskiy: zhizn' $i$ trudy osnovopolozhnika sovremennoy partologii [La vida y obra del fundador de la estasiología contemporánea], Izd-vo Mosk, Moscú, $2^{a}$ ed., 2017. 
debe, más allá de la decisiva inexistencia de unos papeles personales del pensador, al carácter relativamente apátrida de su figura, lo que ha disipado la posibilidad de que una comunidad académica nacional lo considerase como propio: judío liberal nacido en el extremo oriental del Imperio Ruso, emigrado relativamente joven a París donde se instaló durante sus dos décadas más productivas a nivel intelectual (1883-1903), regresó a una Rusia que se le hacía extraña y se comprometió políticamente, sin éxito, para tratar de impulsar al país en la senda constitucional. El contenido de la rica correspondencia dirigida por Ostrogorski a Lévy-Bruhl a la que me refería previamente, en gran parte inédita, ilumina varios de esos extremos oscuros de su biografia ${ }^{15}$. Como ahora se verá en estas notas biográficas, la trayectoria de Ostrogorski muestra que su faceta de científico político, concretada en su intensa dedicación al estudio de los partidos políticos, tuvo un carácter vocacional frente a su dedicación más interesada materialmente a disciplinas con un mayor reconocimiento en aquel momento como el derecho y la historia.

Ostrogorski nació en 1854 en Semiatyce (provincia de Grodno) ${ }^{16}$, localidad emplazada en la "Zona de Residencia", la franja occidental del Imperio Ruso donde se permitía el asentamiento de la población de origen judío. Su padre, de pensamiento avanzado, le formó en la haskalá, movimiento ilustrado que defendía tanto la integración de los judíos en los ámbitos intelectuales y seculares como el reconocimiento de sus derechos como ciudadanos de los países en los que vivían ${ }^{17}$. En 1871 se trasladó a San Petersburgo para estudiar derecho o ciencias administrativas en la Facultad de Derecho de la Universidad Imperial $^{18}$. Destacó la influencia que recibió de algunos profesores como Ivan $\mathrm{E}$. Andreevsky ("derecho administrativo"), de ideas constitucionalistas, Piotr Redkin ("enciclopedia de derecho y ciencias políticas"), rector de la universidad, hegeliano y positivista, Seymon V. Pakhman ("derecho y proceso civil") o Alexander D. Gradovsky ("derecho público ruso y de Europa occidental"), especializado en los sistemas constitucionales europeos y de Estados Unidos, futura especialidad de Ostrogorski. Gradovsky dirigió su investigación doctoral realizada durante la segunda mitad de 1875 sobre la ley de prensa en Francia y facilitó su inmediato acceso al Ministerio de Justicia dirigido por Konstantin Palen.

$\mathrm{Su}$ trabajo en la rama legislativa, donde se revisaban las leyes y se participaba en la discusión de proyectos legislativos, fue muy bien valorado, lo que le valió continuos y rápidos ascensos hasta que en 1882 se convirtió en jefe de esa importante rama. Ostrogorski aprovechó esta etapa para preparar un proyecto con el que convertir su capital científico en capital económico: un

15 Está correspondencia incompleta está conformada por unas 80 cartas escritas entre 1898 y 1921. Quagliariello dio cuenta de parte de ellas en un artículo que pasó prácticamente desapercibido Gaetano Quagliariello, "Contributto alla biografia di Ostrogorski.", Ricerche di storia politica, vol. 10, 1995, pp. 7-30.

16 "Dossier élève de Moisei Ostrogorski”, Mission Archives, Centre d'Histoire de Sciences Po (Paris).

17 Lital Levy, "The Nahda and the Haskala: A comparative reading of 'Revival' and 'Reform", Middle Eastern Literatures, vol. 16, 3, 2013, pp. 300-396.

18 No está del todo claro si estudió una cosa o la otra, pero parece más probable la segunda posibilidad. Sobre la infancia, la juventud y los estudios rusos de Ostrogorski: Igor V. Andrev, M.Ya. Ostrogorskiy: zhizn' i trudy osnovopolozhnika sovremennoy partologii, op. cit., pp. 16-44. 
anuario jurídico con información sobre juristas rusos y estadística judicial que iria actualizando durante el resto de su vida, convirtiéndole en un nombre conocido entre los abogados del país ${ }^{19}$. Cuando Ostrogorski pretendía convertirse en juez, el asesinato en 1881 del zar relativamente aperturista Alejandro II y la consiguiente ola represiva cambió sus planes, impulsándole a emigrar a Francia.

Ostrogorski se instaló en París en 1883, en la etapa de los gobiernos de los conocidos como "republicanos oportunistas" (Léon Gambetta y Jules Ferry principalmente), durante la cual se asentó el régimen parlamentario de la III República y se aprobaron grandes leyes progresistas. En París, se matriculó en la ELSP, institución impulsada en 1871 por Émile Boutmy e Hippolyte Taine tras la humillante derrota en la guerra franco-prusiana con el objetivo de formar, desde una perspectiva liberal, a unas élites políticas y administrativas de origen burgués ${ }^{20}$. Tras unos primeros años difíciles financieramente, la École parecía asentarse y desarrollar uno de sus objetivos iniciales, una formación científica sobre los últimos fenómenos políticos que fuese más allá de la lucrativa tarea que acaparaba sus esfuerzos: la preparación para los concursos de la alta administración ${ }^{21}$. Ante la Asamblea General de 1884, Boutmy se felicitaba por el incremento de las "inscripciones de conjunto"-orientadas a esa formación cientifica desinteresada-, frente a las "inscripciones parciales" 22.

Nuestro emigrado ruso era uno de esos estudiantes de "conjunto" que, además, inauguraba la nueva section générale (o de "historia y derecho público"), cuyo objetivo era impulsar esa vertiente cientifica de la institución. Sus compañeros franceses, por lo general, estudiaban o habian estudiado derecho y, en muchos casos, se convertirian en personajes relevantes de la vida politica y de

19 Ibid., pp. 45-50. Ostrogorski ya había publicado previamente unos libros escolares de historia rusa. Del segundo de ellos, debido a su éxito en los institutos del Imperio hasta la Revolución de 1917, se publicarian 35 reediciones (pp. 34-35, 51-53). Moisei Ostrogorski, Khronologiya russkoy istorii s sinkhronisticheskim obzorom vseobshchey $i$ perechnem zamechatel'nykh lyudey i gosudarstvennykh deya teley kazhdogo tsarstvovaniya [La cronologia de la historia de Rusia con una panorámica de la historia universal e indice de personas ilustres y hombres de Estado de cada reinado], Pratc, San Petersburgo, 1872; Istoriya Rossii s kartinkami i voprosami dlya povto reniya dlya narodnykh uchilishch [Historia de Rusia con ilustraciones $y$ cuestiones para repasar para las escuelas populares], P. P. Merkuryeva, San Petersburgo, 1874. Como confesaría años después a Lévy-Bruhl, la actualización de estos trabajos jurídicos e históricos a la que dedicaba unos dos meses al año, le resultaba tediosa, pero le reportaba unos importantes ingresos que le permitian dedicarse el resto del año a sus investigaciones politicas. Carta de 27/28-11-1910 (IMEC, LVB7 dossier 6). Algo a lo que también se refiere su amigo parisino Alfred Berl, en uno de los dos obituarios conocidos de Ostrogorski: Alfred Berl, "Ostrogorski", La Tribune juive: organe des juifs de Russie, vol. 71, 6-5-1921, p. 1.

20 Véanse los expresivos manifiestos fundacionales de la institución: Émile Boutmy, Ernest Vinet, Projet d'une Faculté libre des sciences politiques, Adolphe Lainé, París, 1871; Quelques idées sur la création d'une faculté libre d'enseignement supérieur, Adolphe Lainé, Paris, 1871; Hippolyte Taine, "Fondation de l'École libre des Sciences politiques", en Derniers essais de critique et d' histoire, , Hachette, Paris, 3a ed., 1903 [1871], pp. 134-149.

${ }^{21}$ Sobre la tensión entre ambos propósitos de la institución: Pedro L. López Herraiz, Formar al hombre de Estado. Génesis y genealogía de la École libre des sciences politiques, Dykinson-Carlos III, Madrid, 2019, pp. 157-179.

22 Émile Boutmy, École Libre des Sciences Politiques. Rapport présenté à l'Assemblée Générale 25-2-1884, Georges Chamerot, Paris, 1884. En Archives d'Histoire Contemporaine (Centre d'Histoire de Sciences Po, París; en adelante AHC), Fonds École libre des sciences politiques, 1872 1945 (en adelante 1 SP), 19 dr 1 sdr b. 
Pedro L. López Herraiz

otros campos ${ }^{23}$. En sus dos años como estudiante, Ostrogorski cursó catorce asignaturas, varias de ellas más o menos jurídicas ${ }^{24}$, en las que adquiriría muchos de los conocimientos básicos y las preocupaciones temáticas que impulsarian sus posteriores investigaciones sobre los partidos politicos y sobre los derechos de las mujeres. Entre ellas, destaca el curso de Histoire constitutionnelle de l'Europe depuis 1789, impartido por el director de la ELSP, Boutmy, consistente en un estudio de la historia constitucional francesa, norteamericana e inglesa ${ }^{25}$. Igualmente, Ostrogorski cursó dos asignaturas de historia política: Histoire parlementaire et législative de la France de 1789 a 1852, impartida por Alexandre Ribot y Francis Charmes; e Histoire politique contemporaine - Tableau de l'Europe contemporaine, impartida por Anatole LeroyBeaulieu, en la que se estudiaban los últimos acontecimientos de varios países prestando especial atención a los partidos politicos. En distintas coordenadas disciplinares se situaba el curso de Législation civile comparée, impartido por Jacques Flach, que serviria de base a Ostrogorski para su posterior investigación sobre los derechos de las mujeres.

Los excelentes resultados académicos del estudiante ruso en la École le permitieron integrarse en sus espacios de investigación. En 1884 Ostrogorski se inscribió en la Société des anciens élèves et élèves (SAEE) ${ }^{26}$, que se acababa de ligar a los recientemente creados groupes de travail y a los Annales de l'École libre des sciences politiques (AELSP o Annales) 27. En el seno de la "sección de finanzas y legislación" de la SAEE, Ostrogorski presentó sendas conferencias sobre dos temas de acento constitucional relacionados con algunas de sus preocupaciones académicas: la "supresión de la censura teatral" (12-3-1886) y la "protección a brindar a las minorías según los publicistas americanos" (4-2-1887) ${ }^{28}$. Durante la primavera de 1887, en el marco del groupe de travail de "Derecho Público y

$23 \mathrm{Si}$ atendemos a los estudiantes que, habiendo terminado sus estudios al tiempo que Ostrogorski (1885), seguian formando parte de la Société des élèves et anciens élèves en 1899, nos encontramos con perfiles como los de Fernand Auburtin, maître de requêtes del Consejo de Estado o Louis Barthou, republicano moderado y presidente del consejo de ministros. Annuaire de la Société des anciens élèves et élèves de l’École Libre des Sciences Politiques, année 1899, FirminDidot, París, 1900.

24 "Dossier d'élève de Moisei Ostrogorski", Mission Archives. Además de las tres asignaturas que se señalan a en el cuerpo del artículon, Ostrogorski cursó, entre otras, las materias de Droit de gens (Théophile Funck-Brentano), Finances françaises et étrangères: le budget, les revenus publics et l'emprunt (Alfred de Foville y René de Laboulaye) y Finances françaises et étrangères: des revenus publics et des impôts (Léon Say y René Stourm).

25 Esta asignatura se completaba con unas conferencias a cargo de Verginaud en las que se abría el marco geográfico a otros países de Europa occidental. Los programas de estos cursos están disponibles en Brochures des cours 1883-1884 y 1884-1885 (AHC, 1 SP 3 dr 1 sdr a). Algunas de estas cuestiones no aparecen en los programas de los brochures des cours, pero sí en los apuntes de Sylvius du Boys (AHC, 1 SP 4 dr 1 sdr a y sdr b).

26 Annuaire de la Société des anciens élèves et élèves de l'École Libre des Sciences Politiques, exercice 1883-1884, París, 1884, p. 13.

27 El triángulo de estudios científicos conformado alrededor de la SAEE, los groupes de travail y los Annales está expresado en una carta de 20-1-1885, dirigida a todos los estudiantes y antiguos estudiantes por Max Botton, director de la SAEE. AHC, 1 SP 20 dr 2 sdr a.

28 "Chronique de l'École 1886 (2)", Annales de l'École libre des sciences politiques, vol. 1, 1886, p. 322; Annuaire de la Société des anciens élèves et élèves de l'École Libre des Sciences Politiques, exercices 1885-1889, París, 1890, pp. 23-24. 
Privado" dirigido por Gabriel Alix, André Lebon y Ribot, el pensador ruso abordó en tres sesiones el análisis de la "Organización de los partidos políticos en Estados Unidos", con las que comenzaba un giro disciplinar hacia la ciencia política. Estas ponencias fueron la base de los cuatro artículos que Ostrogorski publicaría en los Annales entre 1888 y $1889^{29}$. En esta misma revista escribiria varias reseñas entre los años 1891 y 1893, algunas de ellos sobre manuales de derecho público austriaco y belga o sobre los anuarios políticos de su amigo Carl Hilty, un conocido publicista suizo ${ }^{30}$. A partir más o menos de ese periodo, su colaboración con la École se fue reduciendo hasta desaparecer.

Aunque sus artículos publicados en los AELSP tuvieron cierta repercusión en Francia, Ostrogorski alcanzó mayor notoriedad en aquel momento con su libro sobre La femme au point de vue du droit public, con el que ganó el Prix Rossi de derecho constitucional convocado por la Facultad de Derecho de París en 1891 sobre esa misma cuestión ${ }^{31}$. Sin embargo, no se trataba más que de un paréntesis en su intensa dedicación al estudio de los partidos que incluiria ya, en esta última década del siglo XIX, viajes a Estados Unidos y, sobre todo, a Inglaterra para realizar en la linea de la emergente ciencia politica una observación directa del fenómeno. Bajo el padrinazgo de la principal figura de esta corriente, el autor norirlandés James Bryce ${ }^{32}$, Ostrogorski iría preparando su gran obra, la cual no vería la luz hasta el año 1902, cuando se publicó la traducción al inglés, Democracy and the organization of political parties, con una breve antelación respecto del original francés. Gracias a la correspondencia con su editor inglés (George A. Macmillan) y con el propio Bryce, se conocen los avatares del largo proceso de creación de esta obra ${ }^{33}$.

Sin embargo, en esta correspondencia con figuras británicas, Ostrogorski no se refirió a un dato que pudo tener que ver en los continuos retrasos en la finalización del texto final: su ferviente compromiso en la lucha dreyfusard que

29 En realidad, estos cuatro artículos conformaban un solo trabajo que, a pesar de que todavía no se apoyase sobre la investigación de campo, presentaba varios de los elementos básicos que servirian de base para la redacción de su futuro libro. Moisei Ostrogorski, "De l'organisation des partis politiques aux États-Unis", Annales de l'École libre des sciences politiques, vol. 3, 1888, pp. 43-72, 235-267, 520-538, vol. 4, 1889, pp. 12-30.

30 Moisei Ostrogorski, "Compte rendu de "Das Oesterreichische Staatsrecht", Dr. L. Gumplovicz", Annales de l'École libre des sciences politiques, vol. 7, 1892, pp. 160-161; "Compte rendu de "Das politische Jahrbuch der Schweizerischen Eidgenossenschaft", Dr. C. Hilty", Annales de l'École libre des sciences politiques, vol. 7, 1892, pp. 161-162; "Compte rendu de "Das Staatsrecht des Königreichs Belgien" M. Vauthier", Annales de l'École libre des sciences politiques, vol. 7, 1892, pp. 736-738; "Compte rendu de "Das politisches Jahrbuch der Sweizerischen Eidgenossenschaft", Dr. C. Hilty”, Annales de l'École libre des sciences politiques, vol. 8, 1893, pp. 546-549.

31 Moisei Ostrogorski, La femme au point de vue du droit public. Étude d'histoire et de législation comparée, Arthur Rousseau, París, 1892.

32 Sobre la figura de James Bryce, sus estudios sobre partidos y élites y su rol en la formación de la Sociedad de Naciones véase la tan reciente como valiosa investigación de Héctor Domínguez Benito, James Bryce y los fundamentos intelectuales del internacionalismo liberal (1864-1922), Centro de Estudios Políticos y Constitucionales, Madrid, 2018.

33 Correspondencia presentada por Gaetano Quagliariello, Politics Without Parties. Moisei Ostrogorski and the Debate on Political Parties on the Eve of the Twentieth Century, op. cit., pp. 2534. 
marcó la vida política francesa desde el año 1898. Ya en Rusia en 1909, se expresaba de la siguiente manera: "quizás hace falta recordar en qué situación estaba Francia hace diez años, cuando todo parecía derrumbarse, justicia, verdad, honestidad elemental, sentido común. Por azar, saqué ayer de las estanterias de mi biblioteca un volumen del Affaire Dreyfus, de J. Reinach. Cuando ojeaba las páginas, creía revivir mi propia vida" 34 . Más allá de su afinidad ideológica con este movimiento, lo cierto es que Ostrogorski encontró en aquel entorno normalien de fuerte compromiso dreyfusard, encabezado por Lucien Herr, que se superponía con el grupo de sociólogos durkheimianos (Marcel Mauss, François Simiand y el propio Lévy-Bruhl) ${ }^{35}$, un espacio intelectual afin que valoraba positivamente sus investigaciones. Así, sus últimos años en Francia se caracterizaron también por la participación en algunos proyectos académicos impulsados por el carismático bibliotecario de la École normale supérieure, Herr ${ }^{36}$.

Tras su vuelta a Rusia en 1903, Ostrogorski se mantuvo muy pendiente de la recepción de su obra, que fue especialmente positiva en Francia y Estados Unidos, en contraste con la escasa atención y las críticas provenientes de Inglaterra 37 . En un primer momento, Ostrogorski se sentía ajeno a los avatares rusos: "yo miro todo aqui, hombres y cosas, un poco como extranjero"38. Sin embargo, el aceleramiento de la situación política previo a la Revolución de 1905 le empujó a comprometerse políticamente, principalmente a través de su protagonismo en la Unión para la consecución de los plenos derechos del pueblo judio que celebró su primer congreso en Vilna en abril de $1905^{39}$. Ante el decisivo

34 Carta de Ostrogorski a Lévy-Bruhl 6-4-1909 (IMEC, LVB7 dossier 6). E1 compromiso dreyfusard de Ostrogorski se desprende también de las cartas dirigidas a Lévy-Bruhl de 14-91899 (IMEC, LVB7 dossier 2) y 8-3-1904 (IMEC, LVB7 dossier 3).

35 Robert J. Smith, "L'atmosphère politique à l'École Normale Supérieure à la fin du XIX siècle", Revue d'histoire moderne et contemporaine, vol. 20, 2, 1973, pp. 248-268; Vincent Duclert (ed.), Savoir et engagement. Écrits normaliens sur l'affaire Dreyfus, Éditions Rue d'Ulm-Presses de l'École normale supérieure, París, 2006.

$36 \mathrm{El}$ aprecio de Ostrogorski por Herr, quien seguramente fue junto a Bryce y Lévy-Bruhl uno de los principales lectores de los borradores de su obra, se advierte en las habituales peticiones de noticias sobre él a Lévy-Bruhl. Atiéndase principalmente a la carta de 3-8-1903 (IMEC, LVB7 dossier 2), aunque las referencias a Herr son múltiples desde su vuelta a Rusia. Fue este el que posiblemente facilitó la publicación de un artículo que adelantaba parte de su libro en la liberal Revue de Paris y el que le puso en contacto con su editor francés, la casa Calmann-Lévy. Igualmente contó con él para dos proyectos, uno temporalmente exitoso y otro fracasado. E1 primero, la revista Notes Critiques - Sciences Sociales (1900-1906), especializada en reseñar bibliografia extranjera en ciencias sociales, contaba con el autor ruso entre sus colaboradores permanentes. El segundo pretendió ser un semanario de orientación izquierdista, una herramienta política basada en el conocimiento riguroso de la vida política francesa en la que Ostrogorski podría haber emprendido el estudio de los partidos franceses. Charles Andler, Vie de Lucien Herr (1864-1926), Les Éditions Rieder, París, 1932, pp. 136-141; Marcel Fournier, Marcel Mauss, Fayard, París, 1994, pp. 220-225; Jennifer Mergy, "On Durkheim and "Notes critiques»", Durkheimian Studies / Études Durkheimiennes, vol. 4, 1998, pp. 1-2.

37 Además de su correspondencia con Lévy-Bruhl entre los años 1903 y 1904 (IMEC, LVB7 dossier 3), véase Gaetano Quagliariello, Politics Without Parties. Moisei Ostrogorski and the Debate on Political Parties on the Eve of the Twentieth Century, op. cit., pp. 34-35.

38 Carta de Ostrogorski a Lévy-Bruhl de 6-3-1903, IMEC, LVB7 dossier 3.

39 En adelante, Unión del pueblo judio. Igor V. Andrev, M.Ya. Ostrogorskiy: zhizn' $i$ trudy osnovopolozhnika sovremennoy partologii, op. cit., pp. 107-108. 
Manifiesto del 17 de Octubre ("por la mejora del sistema político"), por el cual Nicolás II reconocía varias libertades cívicas y convocaba unas elecciones por sufragio universal masculino para la elección a través de un complejo sistema electoral de curias de un órgano legislativo (la Duma Imperial) ${ }^{40}$, Ostrogorski escribió en septiembre de 1905 un artículo en el órgano de la izquierda Kadet, Nasha zhizn', bajo el título de "El Manifiesto de 17 de Octubre y la Asamblea Constituyente" ${ }^{41}$, en el que se proponía analizarlo desde la perspectiva de un "constitucionalista" 42 .

En el seno de la Unión del pueblo judio, Ostrogorski, que pertenecía al sector liberal-progresista encabezado por Maxim Vinaver y Sliozberg Borisovich (enfrentado al sector sionista en el que destacaba Vladimir Jabotinsky) ${ }^{43}$, fue designado como candidato por su provincia, Grodno. En las elecciones de primer grado saldría elegido por la curia urbana y, tras las negociaciones entre los electores judíos y los campesinos, sería elegido en segundo grado como diputado para la primera Duma en abril de $1906^{44}$. Aunque cercano a los kadets, se mantuvo fiel a su opinión contraria a los partidos al no inscribirse en ninguno y luchar en el seno de la Unión del pueblo judio contra las pretensiones de los sionistas de establecer una disciplina partidista.

En el breve periodo de funcionamiento de la Duma, poco más de dos meses, Ostrogorski destacó como un activo diputado ${ }^{45}$. El presidente de la cámara, el kadet Serguei Muromtsev, recurrió a él para la conformación de una comisión encargada de la creación de un reglamento parlamentario que asegurase el correcto funcionamiento de la cámara, algo especialmente necesario para transmitir al pueblo una imagen de estabilidad y utilidad. Aunque el propio Ostrogorski exagerase al afirmar que había sido "el consultor de la Duma para cuestiones de derecho constitucional y casi el árbitro de hecho del procedimiento parlamentario"46, lo cierto es que se le encargó realizar importantes informes para esta comisión presidida por Kovalevsky. Uno de sus posicionamientos más polémicos en este marco fue su rechazo a que el método de elección de las comisiones parlamentarias estuviese controlado por los partidos. Igualmente, jugó un rol importante tanto en la comisión sobre la igualdad civil, en la que presentó un informe cuyo objetivo era terminar con la "Zona de Residencia” de la

40 Terecen Emmons, "Russia's first national elections", en François-Xavier Coquin, Céline Gervais-Francelle (eds.), 1905. La première revolution russe, Éditions de la Sorbone, París, 1986, pp. 31-35; Marc Szeftel, "Le Manifeste du 17 Octobre et son rôle dans l'évolution constitutionnelle de l'Émpire", en François-Xavier Coquin, Céline Gervais-Francelle (eds.), 1905. La première revolution russe, Éditions de la Sorbone, París, 1986, pp. 14-30.

41 "Kadet" hace referencia al "Partido Democrático Constitucional", fundado ese mismo año y que sería la fuerza con más diputados en la primera Duma.

42 Moisei Ostrogorski, "Manifest 17 oktyabrya i Uchreditel'noye sobraniye" ["Manifiesto del 17 de Octubre y la Asamble constituyente"], Nasha zhizn', 1905.

43 Christoph Gassenschmidt, Jewish Liberal Politics in Tsarist Russia, 1900-14. The Modernization of Russian Jewry, Macmillan, Londres, 1995, pp. 19-31.

44 Igor V. Andrev, M.Ya. Ostrogorskiy: zhizn' i trudy osnovopolozhnika sovremennoy partologii, op. cit., pp. 120-134.

45 Sobre la acción de Ostrogorski como diputado: Ibid., pp. 134-160.

46 Carta de Ostrogorski a Lévy-Bruhl de 27-8-1906, IMEC, LVB7 dossier 4. 
población judía, como en la paralela lucha en defensa de los derechos de los judíos ante actos como el pogromo de Bialystok (Grodno), perpetrado con la aquiescencia y la colaboración del ejército y la policía zarista. Un último campo de su acción parlamentaria fue el del arbitraje internacional. A partir de su cooperación con el futuro premio nobel de la paz, Paul d'Estournelles de Constant, Ostrogorski y Kovalevsky establecieron, siguiendo el ejemplo francés, un grupo parlamentario de arbitraje internacional al que se sumaron unos 200 diputados ${ }^{47}$. Ambos formarian parte del comité directivo que sería enviado a Londres para participar en la Conferencia Interparlamentaria por la Paz. Sin embargo, no pudieron tomar parte de sus sesiones, ya que en la víspera de su inauguración (22 de julio) la Duma sería disuelta.

Desde la perspectiva de Ostrogorski, la primera Duma fue un episodio importante de la historia constitucional rusa, una oportunidad perdida para la homologación del país con las democracias occidentales. Debido a ello, y a pesar de añorar sus "queridos estudios", no consideraba que pudiese "desertar del campo de batalla" 48 . Sin embargo, ese campo de batalla se recrudecía con la reactivación electoral de las fuerzas tradicionalistas, la represión zarista y la actividad de grupos violentos antisemitas, las "centurias negras", que en su periódico habian pedido la eliminación física de Ostrogorski. Aunque, seguramente, su mayor dificultad vendría de la ruptura de la Unión del pueblo judio y de los ataques que recibía por parte del sector sionista. Ostrogorski fue elegido en primer grado, pero no en segundo, por lo que, ante los fraudes electorales perpetrados por el gobierno, trató de impugnar sin éxito los resultados $^{49}$. A principios de 1907, la segunda Duma, dominada todavía por las fuerzas enfrentadas al zar, sería disuelta por un ukase de este que rompía con el Manifiesto del 17 de Octubre al cambiar la ley electoral para otorgar un peso mucho mayor a los terratenientes. Sin demasiadas esperanzas, se presentó a estas terceras elecciones. El 5 de noviembre de 1907 le comunicaba a Lévy-Bruhl el dramático resultado de los comicios, en los que habrian vencido los partidarios del absolutismo, muchos de ellos "bandidos", y, también, su retorno a la vida que llevaba antes de los acontecimientos de 1905: "vuelvo a mis estudios, pero no vuelvo a entrar a una torre de marfil. Procuraré servir a la sociedad a través de los medios que me quedan"50.

Esta última no era una fórmula vacía ya que, efectivamente, Ostrogorski imprimió a sus nuevos trabajos sobre partidos un carácter divulgativo que no tenian previamente. Entre 1907 y 1912 actualizaria sus investigaciones sobre el fenómeno partidista en Inglaterra y Estados Unidos, y reduciría el tamaño de su gran obra de 1903. Esto tendría como fruto dos publicaciones. Si la primera trataba exclusivamente sobre Estados Unidos, la segunda, en francés, incluía también el caso inglés: Democracy and the party system in the United States. A

47 Moisei Ostrogorski, "Déclaration faite au nom de la Commission du Règlement, à la séance de la Douma d'Empire du 21 Juin 1906", en Paul Estournelles de Constant (ed.), Groupe parlementaire français de l'arbitrage international: Année 1906, Delagrave, París, 1906, pp. 95-97.

48 Carta de Ostrogorski a Lévy-Bruhl de 27-8-1906, IMEC, LVB7 dossier 4.

49 Ostrogorski narró a Lévy-Bruhl los pormenores de esta campaña en su carta de 27-2-1907 (IMEC, LVB7 dossier 5).

50 Carta de 5-11-1907, IMEC, LVB7 dossier 5. 
study in extra-constitutional government (1910) y La démocratie et les partis politiques (1912) ${ }^{51}$. Tras ello, Ostrogorski, sin renunciar a su enfoque histórico, viró hacia un tema más propiamente constitucional: un estudio sobre las transformaciones recientes de la constitución inglesa, desde la década de 1860 hasta ese momento. Aunque se hayan sobrevalorado las intenciones de este texto $^{52}$, lo cierto es que se trataba de un trabajo breve destinado a una revista rusa, Vestnik Evropy (publicación de inclinación liberal dirigida por Kovalevsky), que Ostrogorski no pretendió que tuviese más recorrido en Europa occidental ${ }^{53}$. Tras la publicación de cuatro artículos en esa revista durante el año 1913, debió esperar hasta 1916 para publicar su trabajo en un libro ${ }^{54}$.

Debido a una grave enfermedad cerebral, Ostrogorski se había instalado en un sanatorium en Alemania ${ }^{55}$, sorprendiéndole el comienzo de la Gran Guerra allí, lo que imposibilitó su salida del país hasta finales de 1915 y su vuelta a Rusia, con la salud relativamente recuperada, hasta $1916^{56}$. Ostrogorski se sumó a la creación por parte de Kovalevsky y Pitrim Sorokin, entre otros, de la Asociación Rusa de Sociología (1916) ${ }^{57}$, pero no aceptó una catedra de derecho constitucional en el Instituto Psiconeurológico en el que participaban los dos profesores referidos $^{58}$. El autor ruso acogió favorablemente la Revolución de febrero de 1917 y la caída del zar59. En ese tiempo, retomó su implicación en el Grupo del pueblo judio, participando en su Comité Central, que apoyaba al gobierno provisional en su decisión de continuar la guerra contra los imperios centrales. No tuvo Ostrogorski la misma consideración respecto del creciente poder bolchevique, del que temía pudiese provocar la derrota militar de Rusia ${ }^{60}$. A través del testimonio

51 Moisei Ostrogorski, Democracy and the party system in the United States. A study in extraconstitutional government, Macmillan, Nueva York, 1910; La démocratie et les partis politiques, Calmann-Lévy, París, 1912.

52 Igor V. Andrev, M.Ya. Ostrogorskiy: zhizn' i trudy osnovopolozhnika sovremennoy partologii, op. cit., pp. 120-134; Gaetano Quagliariello, Politics Without Parties. Moisei Ostrogorski and the Debate on Political Parties on the Eve of the Twentieth Century, op. cit., pp. 152-157. Moisei Ostrogorski, La costituzione inglese, Maria Rosaria Pelosi (trad.), Alfredo Guida, Nápoles, 1998 [1916].

53 Véanse las afirmaciones del propio Ostrogorski sobre la naturaleza de este trabajo en su correspondencia dirigida a Lévy-Bruhl: cartas de 11-8-1912, 20-10-1912 y 20-2-1913, IMEC, LVB7 dossiers 7 y 8.

54 En el original ruso el título era algo más largo que el que utiliza Quagliariello en su reedición: Moisei Ostrogorski, Konstitutsionnaya evolyutsiya Anglii $v$ techeniye posled nego poluveka [La evolución constitucional de Inglaterra durante el último medio siglo], Usova, Petrogrado, 1916.

55 Sobre su enfermedad: carta de la hermana de Ostrogorski, Adeline Ostrogorskaya a LévyBruhl de 24-11-1913, IMEC, LVB7 dossier 9.

56 Las localizaciones y la situación de Ostrogorski las conocemos por sus cartas a Lévy-Bruhl de 26-9-1915, 19-3-1916, 21-3-1916, 18-4-1916, IMEC, LVB7 dossier 8.

57 Sobre los últimos años de vida de Ostrogorski en Rusia (1916-1921), véase: Igor V. Andrev, M.Ya. Ostrogorskiy: zhizn'i trudy osnovopolozhnika sovremennoy partologii, op. cit., pp. 246-270.

58 Aunque sí que impartió algunos cursos libres en tal institución. Carta de Ostrogorski a LévyBruhl de 21-8-1916, IMEC, LVB7 dossier 8.

59 Carta de Ostrogorski a Lévy-Bruhl de 10-4-1917, IMEC, LVB7 dossier 8.

60 Carta de Ostrogorski a Lévy-Bruhl de 20-8-1917, IMEC, LVB7 dossier 8. 
de Sliozberg conocemos su suerte tras la Revolución de Octubre61, cuando sus condiciones de vida se vieron tremendamente afectadas por el bloqueo de sus ahorros y la inflación. Así, dependia de su salario por la impartición de unos cursos de "politica estatal", de "historia de los estudios políticos" y de "instituciones politicas y sociales en las nuevas democracias mundiales", en la Universidad de Petrogrado. Igualmente, participó en una comisión sobre el tratado de paz de Brest-Litovsk (1918) cuya función era prestar asistencia jurídica a la población judía en la inestable franja occidental del antiguo Imperio ruso, en la que habían surgido nuevos estados mientras que otros territorios pasaban a formar parte, brevemente, de Alemania. De nuevo gravemente enfermo, Ostrogorski pasaría sus últimos días en la "Casa de la Ciencia" de Petrogrado, institución creada para acoger a los científicos que habían visto diezmados sus ingresos, falleciendo en marzo de 1921.

Como vemos, la trayectoria profesional y académica de Ostrogorski se situó, a nivel disciplinar, entre dos polos -derecho constitucional y ciencia politica-, y, a nivel geográfico, entre, principalmente, Rusia y Francia, con algunas incursiones académicamente relevantes en Inglaterra y Estados Unidos. Es esa primera tensión (aparente) en el nivel disciplinar, la que interesa a este trabajo y en la que se profundiza, atendiendo al contenido de las investigaciones del autor ruso, en los dos siguientes epígrafes.

\section{LA IMPORTANCIA DE LAS "FUERZAS" POLITTICAS EN DETRIMENTO DE LAS "FORMAS".}

\subsection{Los partidos políticos como ángulo muerto de los estudios juridicos.}

Como es bien sabido, los partidos actuales poco tienen que ver con las primeras realidades a las que se otorgó esa denominación ${ }^{62}$. Situándonos en un nivel muy superficial y en el periodo que nos interesa, debe subrayarse la profunda transformación de los partidos entre las últimas décadas del siglo XIX y las primeras del XX, durante las cuales los conocidos como "partidos de notables" que centraban su actividad en la vida parlamentaria fueron desplazados por los "partidos de masas", organizados y anclados en la sociedad y con la pretensión de controlar la actividad de las cámaras legislativas. Aunque sin referirse a la tipologia "notables-masas", fue esta transformación de la que Ostrogorski dio cuenta. La principal objeción que se dirigía a los partidos de notables, a la que me referiré como "objeción monista", había sido que desafiaban el sustento filosófico fundamental de la modernidad ilustrada, el principio de unidad y la búsqueda del bien común ${ }^{63}$. A pesar de esto, los partidos se fueron configurando,

61 G. Borisovich Sliozberg, "Posledniye gody M.YA. Ostrogorskogo" ["Los últimos años de M. Ya. Ostrogorski”], La Cause Commune. Quotidien Russe., 22-5-1921, París, p. 2.

62 Para una panorámica de la abundante bibliografía politológica sobre modelos de partido: André Krouwel, "Party Models", en Richard S. Katz, William Crotty (eds.), Handbook of Party Politics, Sage, Londres, 2006, pp. 249-269.

63 Con el enfoque de historia de la cultura constitucional propio de la escuela florentina de historia del derecho, Massimiliano Gregorio ha llevado a cabo un penetrante estudio sobre las reflexiones de los juristas (principalmente italianos) en torno a la idea de partido politico. El criterio clave que propone para comprender la evolución de estas reflexiones es el de la tensión 
primero en Inglaterra durante el siglo XVIII y después en la Europa continental durante el XIX, como un cuerpo intermedio imprescindible para poner en contacto al Estado con la opinión pública y para ordenar la vida parlamentaria64.

Debido a dos procesos paralelos que tuvieron lugar durante el siglo XIX -la parlamentarización y la extensión del sufragio-, los partidos ganaron protagonismo al mismo tiempo que evolucionaban hacia el modelo organizativo de masas ${ }^{65}$. Fue en ese contexto, en el que a la "objeción monista" a los partidos se le sumó la "objeción elitista"66, que enfatizaba los problemas derivados de una selección de las élites a través de las organizaciones partidistas, entre ellos, las dificultades de dar cumplimiento al horizonte de representación democrática que estaba en su origen. Normalmente, se considera que el estudio de Michels sobre el Partido Socialdemócrata Alemán (1911) fundó estas críticas de corte elitista ${ }^{67}$. No obstante, esta consideración estaría ignorando la relevancia que tuvieron poco tiempo antes los estudios sobre los vigorosos partidos norteamericanos y el debate sobre el grado de extensión de ese modelo en la política inglesa. En este campo sobresalieron los trabajos de Bryce o de sus, en distinta medida, continuadores Lowell y Ostrogorski. Si bien los dos primeros formaban parte de la sólida comunidad de científicos politicos angloamericanos ${ }^{68}$, el autor ruso, aunque leyese a y fuese leído por los autores de ese entorno, observaba el desarrollo de los partidos en Estados Unidos e Inglaterra a través del prisma de los debates políticos franceses y con las claves disciplinares propias de las ciencias sociales del cambio de siglo.

En Francia, las concepciones monistas de lo social estaban más asentadas debido a la profundidad de la tradición jacobina, lo que retrasó manifiestamente el asentamiento y la aceptación de los partidos como organizaciones que representan la parcialidad social. La desconfianza hacia cualquier cuerpo que mediase entre el pueblo y sus representantes impulsó una legislación especialmente restrictiva en el campo asociativo ${ }^{69}$. Hubo que esperar hasta bien entrada la III República para que el monismo fundador del imaginario republicano dejase ver entre sus grietas los primeros indicios de organización partidista. Algunos hitos en este proceso fueron el surgimiento de los comités electorales republicanos y radicales en las elecciones legislativas de 1881 para la

entre unidad y parcialidad. Massimiliano Gregorio, Parte totale. Le dottrine costituzionali del partito politico in Italia tra Otto e Novecento, Giuffrè, Milán, 2013, pp. 3-34.

64 Joaquín Varela Suanzes-Carpegna, Sistema de Gobierno y Partidos Politicos. De Locke a Park, Centro de Estudios Politicos y Constitucionales, Madrid, 2002.

65 Susan E. Scarrow, "The Nineteenth-Century Origins of Modern Political Parties: the Unwanted Emergence of Party-Based Politics", en Richard S. Katz, William Crotty (eds.), Handbook of Party Politics, Sage, Londres, 2006, pp. 17-19.

66 Agradezco al profesor Eduardo Zimmermann (Universidad de San Andrés, Argentina) que me sugiriese esta clarificadora categorización de las objeciones a los partidos.

67 Robert Michels, Zur Soziologie des Parteiwesens in der modernen Demokratie. Untersuchungen über die oligarchischen Tendenzen des Gruppenlebens, Werner Klinkhardt, Leipzig, 1911.

68 Héctor Domínguez Benito, James Bryce y los fundamentos intelectuales del internacionalismo liberal (1864-1922), op. cit., pp. 67-116.

69 Paula Cossart, Le meeting politique. De la délibération à la manifestation (1868-1939), Presses Universitaires de Rennes, Rennes, 2010, pp. 105-114. 
nominación de unos candidatos que representarian un programa, la creación del Parti Ouvrier Française un año después, o la aprobación de la Ley del 1 de julio de 1901 que extendia la libertad de asociación ${ }^{70}$.

Aun así, el periodo durante el cual Ostrogorski, afincado en París, desarrolló su gran obra (1887-1903), no significó el asentamiento de los partidos de organización permanente, jerárquica y de escala nacional. Estas realidades, débiles e incipientes, convivieron con otras organizaciones más laxas, entre las que destacaban las ligas, de gran relevancia, por ejemplo, durante el affaire Dreyfus ${ }^{71}$. Este carácter incompleto del desarrollo de los partidos en Francia fue precisamente el que impelió al autor ruso a desarrollar un estudio sobre Inglaterra y Estados Unidos con el objetivo de advertir a los franceses de los efectos negativos de la politica partidista. Ya desde sus primeros artículos de finales de la década de 1880, Ostrogorski apuntaba este aliento de fondo en su investigación:

"en Francia, después del triunfo definitivo de la república democrática, cuando, según la expresión corriente, la era de los peligros se ha cerrado y la era de las dificultades comienza, la idea de la organización metódica de los partidos en el territorio se presenta para muchas personas como un remedio $y$, en el momento en que nos encontramos, asistimos a las primeras tentativas de aplicación práctica de estas ideas"72.

Al igual que hicieron los nuevos estudiosos de la politica angloamericanos Bryce, Lowell o Jesse Macy-, Ostrogorski tuvo que superar la relación distante que los dominantes estudios jurídicos habian tenido tradicionalmente respecto de los partidos políticos. Si seguimos al jurista alemán crítico con el positivismo jurídico, Heinrich Triepel, se puede considerar que los partidos políticos, en su relación con el derecho, atravesaron distintas fases. En una primera etapa de enfrentamiento (Bekämpfung), los partidos se opusieron al Ancien Régime hasta derribarlo para alcanzar la libertad politica. Posteriormente, se pasaria a una fase de "ignorancia" (Ignorierung), que seria superada por otra de reconocimiento y legalización (Anerkennung und Legalisierung). Finalmente, y esto es lo que rechazaba este jurista conservador en el contexto weimariano, se habria llegado a una etapa de incorporación constitucional (verfassunsmässingen Inkorporation) ${ }^{73}$. El marco en el que escribía Ostrogorski se situaba, más bien, a caballo entre la segunda y la tercera etapa de Triepel, en un momento en el que los partidos prácticamente no habian sido objeto de estudio por parte de los juristas. E1 positivismo jurídico de la segunda mitad del siglo XIX, al purgar la ciencia legal de elementos no jurídicos y de la influencia de otros saberes como la filosofia, la ciencia politica o la historia, había construido una teoría abstracta en la que el

70 Serge Bernstein, "Naissance des partis politiques modernes", en Serge Bernstein, Michel Winock (eds.), L'Invention de la démocratie, 1789-1914, Seuil, París, 2002, pp. 497-560.

71 Nicolas Roussellier, "Brilliant Failure: Political Parties Under the Republican Era in France (1870-1914)", en Henk te Velde, Maartje Janse (eds.), Organizing democracy. Reflextions on the Rise of Political Organizations in the Nineteenth Century, Palgrave Macmillan, Cham, 2017, pp. 145164.

72 Moisei Ostrogorski, “De l'organisation des partis politiques aux États-Unis (1)”, op. cit., pp. $43-44$.

73 Heinrich Triepel, La constitución y los partidos politicos, Pedro Madrigal Devesa (trad.), Tecnos, Madrid, 2015 [1927]. 
Estado se autojustificaba sin tener que recurrir a la legitimidad popular, siendo los partidos, por tanto, innecesarios ${ }^{74}$. El incipiente discurso disciplinar de la ciencia política de aquel momento aprovechó estos límites de los estudios jurídicos, estereotipando en cierta manera tanto sus defectos como, principalmente, su extensión en un campo tan plural como el de los juristas. Aunque muchas cosas cambiaron desde entonces, lo cierto es que este elemento siguió siendo una constante en la diferenciación emprendida por los politólogos respecto del derecho ${ }^{75}$.

\subsection{La "nueva ciencia política" de Ostrogorski: la observación de las "fuerzas" politicas.}

Ostrogorski participaba de este discurso politológico, aportando la distinción entre el estudio de las "formas" políticas y el de las "fuerzas", y señalando la ignorancia de estas últimas por parte de los juristas. Desde sus reseñas en los Annales, mostró un rechazo explícito por la "escuela jurídica alemana", de la que afirmaba: "que continúe, si le place, purgando la enseñanza del derecho público de todo elemento histórico y filosófico, pero que al menos respete los hechos sin meterlos en la cama de Procusto de sus teorias"76. Bastante tiempo después, en su trabajo de 1916 sobre la reciente historia constitucional inglesa, Ostrogorski volvía a censurar a la "escuela jurídica de la ciencia del estado", ciega a las mutaciones constitucionales, solo apreciables por un enfoque que integrase en la historia constitucional, también, a la historia del derecho parlamentario y de los partidos politicos ${ }^{77}$. Por las fechas y el escueto contenido de estas críticas, $1892 \mathrm{y}$ 1916, se estaria refiriendo, seguramente, a juristas germanos como Georg Jellinek, Paul Laband o Otto Mayer, a los que podrian sumarse el francés Raymond Carré de Malberg y el italiano Vittorio Emanuele Orlando ${ }^{78}$.

Entre estos dos momentos, con el desarrollo de sus grandes investigaciones sobre los partidos, Ostrogorski había asentado estas consideraciones críticas dirigiéndolas en un sentido propositivo: el estudio del funcionamiento real de la política y de las instituciones, yendo más allá de su forma jurídica. Encabezando

74 Massimiliano Gregorio, "Public Law between the Nineteenth and Twentieth Centuries: the epicentre of a cultural earthquake. The European phenomenon and the Italian case study", en Laura Beck Varela, Pablo Gutierrez Vega, Alberto Spinosa (eds.), Crossing legal cultures, Martin Meidenbaur, Munich, 2009, pp. 427-429.

75 Valga como ejemplo la afirmación no demasiado lejana de Giovanni Sartori: "cuando los abogados constitucionales se hicieron cargo de la teoría constitucional los partidos quedaron aún más sumidos en un limbo, pues no adquirieron la condición de sujetos de derecho público hasta después de la Segunda Guerra Mundial". Giovanni Sartori, Partidos y sistemas de partidos, Fernando Santos Fontela (trad.), Alianza Editorial, Madrid, 2a ed., 1992 [1976], p. 34.

76 Moisei Ostrogorski, "Compte rendu de "Das Staatsrecht des Königreichs Belgien" M. Vauthier", op. cit., p. 738.

77 Moisei Ostrogorski, La costituzione inglese, op. cit., p. 27.

78 Sobre la ciencia jurídica del Estado de esta época y las doctrinas de los autores mentados, véanse: Maurizio Fioravanti, Giuristi e costituzione politica nell'Ottocento tedesco, Giuffrè, Milán, 1979, pp. 213-423; La scienza del diritto publico. Dottrine dello stato e della constituzione tra otto e novecento. Tomo I, Giuffrè, Milán, 2001, pp. 451-518; Alain Laquièze, "État de droit e sovranità in Francia", en Pietro Costa, Danilo Zolo (eds.), Lo Stato di diritto. Storia, teoria, critica, 3a ed., Feltrinelli, Milán, 2006, pp. 284-316. 
su obra de 1903 con el lema tocquevilliano -"Hace falta una ciencia política nueva para un mundo totalmente nuevo"79-, reconocia que el camino que pretendía emprender no estaba inexplorado, como mostraban también los trabajos de Montesquieu o Walter Bagehot. Sin embargo, el autor ruso consideraba que iba más allá en ese camino:

"En este en este libro el funcionamiento del gobierno democrático. Pero no son las instituciones las que son objeto de esta obra; no me fijo en las formas políticas, sino en las fuerzas políticas. Hasta ahora nos hemos dedicado demasiado exclusivamente al estudio de las formas políticas. Incluso el método de observación, introducido en la ciencia política con el Esprit des lois, se ha ejercido preferentemente sobre las instituciones, sobre las leyes, ignorando durante largo tiempo, casi totalmente, a los hombres concretos que las crean y las ponen en marcha" 80 .

Los partidos eran aquellas fuerzas que, a pesar de haber modificado profundamente el engranaje constitucional de las democracias inglesa $y$ norteamericana, no habian sido estudiadas más que por algunos pioneros como Bryce, que habian traslado ese método de observación de las formas a las fuerzas politicas. Del propósito que Ostrogorski se marcaba en el prefacio de su obra, daba cumplida cuenta en sus dos volúmenes. La atención a las fuerzas por encima de las formas, o más bien, la atención a cómo las fuerzas transformaban las formas, atravesaba toda su investigación. Así, por ejemplo, cuando analizaba el declive del poder real en Inglaterra, señalaba que este se producía "sin perder formalmente ni una sola de sus prerrogativas" 81 .

Lo cierto es que esta primacía explicativa de las fuerzas por encima de las formas, en la obra de Ostrogorski, tenía como trasfondo la distinción más amplia entre el funcionamiento "real" de la política y el "teórico". Esto se aprecia, por ejemplo, cuando, al estudiar la actividad de las organizaciones de partido inglesas en su base (los wards), Ostrogorski subrayaba la distancia entre la "teoria del Caucus" -una representación democrática de todos los votantes del partido desde la base-, y la realidad: que solo una pequeña fracción de ellos participaban, estando, además, controlados por el secretario local del caucus ${ }^{82}$. La propia normatividad del caucus -no jurídica en este caso-, era también superada por el terco funcionamiento real de la política.

En este marco que oponía las fuerzas a las formas y el funcionamiento real de la política al teórico, tomaba protagonismo un término muy recurrente en los trabajos de Ostrogorski, que incluso aparecería en el título de la edición resumida norteamericana de 191083: "gobierno extra-constitucional", con el que se referia al caucus inglés y al sistema de convenciones estadounidense, las verdaderas fuerzas motoras de un funcionamiento deformado de la constitución ${ }^{84}$. Respecto

79 Moisei Ostrogorski, La démocratie et l'organisation des partis politiques. Vol. I, op. cit., p. 7.

80 Ibid., p. vii.

81 Ibid., p. 9.

82 Ibid., pp. 305-312

83 Moisei Ostrogorski, Democracy and the party system in the United States. A study in extraconstitutional government, op. cit.

${ }^{84}$ Moisei Ostrogorski, La démocratie et l'organisation des partis politiques. Vol. I, op. cit., p. 1; La démocratie et l'organisation des partis politiques. Vol. II, op. cit., pp. 52-53. 
de los Estados Unidos, el autor ruso hacía énfasis en cómo la acción de los partidos había ido pervirtiendo uno a uno el cometido que la Constitución Federal de 1787 había encomendado a casi todas las instituciones ${ }^{85}$. Una muestra clara de esto la encontraba en los comicios presidenciales, en los cuales los elegidos para los colegios electorales estatales, en principio libres según la constitución para elegir al presidente, en la práctica no podían más que adoptar la decisión previa de la convención nacional del partido correspondiente. Más allá de este caso concreto, para Ostrogorski, las administraciones federal y municipal, las cámaras legislativas, el poder judicial o el presidente se habian convertido, en distinta medida, en correas de transmisión de los espurios intereses de las organizaciones de partido, lo que bloqueaba las tareas constitucionales de estas instituciones y minaba tanto su legitimidad como su autoridad ${ }^{86}$.

En sus conclusiones, asumiendo un ambicioso rol de filósofo político, Ostrogorski llevaba esta preponderancia de las fuerzas sobre las formas hasta el punto de plantear una nueva clasificación de las formas de gobierno que superase las taxonomias tradicionales aristotélicas y kantianas basadas en signos externos que no serian más que trampantojos que ocultaban la realidad. Para nuestro autor, en aquel momento histórico, monarquías, repúblicas y democracias podian compartir rasgos esenciales. La diferencia clave entre distintos regimenes radicaba en la fuerza motriz detrás de las instituciones: si se trataba de hombres conscientes de sus derechos y deberes, estariamos ante un gobierno personal y, en consecuencia, responsable, pero si se trataba de hombres reducidos a cosas o a instrumentos, como ocurría con las organizaciones de partido, estariamos ante un gobierno mecánico e irresponsable 87 .

Para Ostrogorski, que las fuerzas primaban sobre las formas se evidenciaba también en la futilidad de muchas reformas legislativas que buscaban acabar con la corrupción y con el dominio partidista de la politica. Así lo demostrarian, por ejemplo, las fallidas experiencias de la introducción del australian ballot o voto secreto en Estados Unidos, que buscaba eliminar la coerción y el mercadeo de votos en las grandes urbes ${ }^{88}$, o la promulgación de la Corrupt Practices Act inglesa de $1883^{89}$. Con acentos liberales, el autor ruso discutía la "virtud fetichista" que se solia otorgar al Estado y a sus leyes para acabar con los efectos perniciosos de los partidos ${ }^{90}$. Y es que, Ostrogorski consideraba que cambiar las formas de la representación (aspectos jurídicos) sin cambiar las fuerzas que hacian uso de ellas, sería inútil. Estas fuerzas no podrian sustituirse mediante ninguna medida

85 Ibid., p. 341.

86 Ibid., pp. 365-372, 508-513.

87 Ibid., pp. 604-606.

88 Ibid., pp. 323-324, 469-478.

89 Moisei Ostrogorski, La démocratie et l'organisation des partis politiques. Vol. I, op. cit., pp. 436-449.

90 Ostrogorski discutía lo que, en su opinión, se había convertido en la panacea para muchos ciudadanos estadounidenses: la legalización de la actividad de los partidos con el objetivo de controlar su actividad. Moisei Ostrogorski, La démocratie et l'organisation des partis politiques. Vol. II, op. cit., p. 603. 
jurídica, sino que requerian de un cambio en la mentalidad de los ciudadanos, en el "habeas animum"91.

Era en este punto en el que Ostrogorski planteaba una ambiciosa y radical alternativa a los partidos que, para bien o para mal, marcaría las lecturas posteriores de su obra y que se resumía en un lema: "A bas le parti et vive la ligue!". Las ligas monotemáticas y temporales, antítesis de los partidos en sus dos caracteres básicos (programas ómnibus y organización permanente) eran, para el autor ruso, la solución lógica, completa y necesaria a todo el daño infligido por los partidos al régimen democrático ${ }^{92}$.

En definitiva, vemos que esa "nueva ciencia política" (la observación de los fenómenos políticos más allá de las formas o instituciones), llamada a explicar un "mundo totalmente nuevo" (el de las fuerzas politicas partidistas), se proyectaba sobre todos los niveles de la obra de Ostrogorski: temáticos, analiticos, explicativos y propositivos. Elementos que le alejaban conscientemente del campo de los juristas y que parecen más que suficientes para que su obra fuese reclamada como fundacional en el campo de la ciencia política moderna. Y, sin embargo, debe insistirse en ello, habría que ser cauteloso al dar carta blanca a la reclamación politológica de Ostrogorski, ya que las fronteras disciplinares principalmente la existente entre el derecho público y la ciencia politica-, no eran tan nítidas en aquel momento como lo son hoy, algo en lo que la obra del pensador ruso no solo no era una excepción, sino que se puede considerar, incluso, como un ejemplo arquetípico. Hay un Ostrogorski que, más allá de los datos biográficos ya presentados, se incardinaba en el campo de los estudios de derecho constitucional.

\section{APARENTES TENSIONES DISCIPLINARES: OSTROGORSKI COMO JURISTA.}

\subsection{La "frialdad" del jurista ante el movimiento por los derechos politicos de las mujeres.}

Hemos visto cómo, tanto en sus primeros trabajos sobre partidos (18881889) como en su último libro (1916), Ostrogorski se mostraba aparentemente alejado de los trabajos de los juristas que le eran contemporáneos. No obstante, uno de sus trabajos intermedios no puede más que descolocar al analista de su obra. En 1892, el autor ruso publicaba La femme au point de vue du droit public. Étude d'histoire et de législation comparée, un libro dificilmente integrable con una minima coherencia en la presentación hecha hasta ahora de su enfoque. Y no simplemente por su título.

Esta obra, premiada por los profesores de la Facultad de Derecho de París con el Prix Rossi de 1891 (quienes consideraron que su investigación llevaba "la huella de un espíritu robusto, que sabe con justicia los hechos y sus matices, y extrae con una sabia moderación la significación que hay que otorgarles para

\footnotetext{
91 Ibid., pp. 683-695.
}

92 Ibid., pp. 618-653. 
favorecer la marcha general de las ideas reformadoras")93, tuvo cierta repercusión ${ }^{94}$, le permitió entrar en contacto con algunos juristas extranjeros y fue traducida a distintos idiomas en los años siguientes ${ }^{95}$. Se trataba de una investigación de derecho comparado sobre la legislación de varios países más o menos desarrollados (Francia, Alemania, Rusia, los países escandinavos, los países de la cultura jurídica del common law, entre otros) respecto de los derechos políticos de las mujeres (corona, sufragio directo e indirecto a nivel nacional y local, libertades de prensa, reunión y asociación, etc.), el acceso a funciones públicas $\mathrm{y}$, en el ámbito privado, las libertades profesionales, de capacidad civil y de instrucción. Una temática que, en la línea de sus otros estudios y de lo preconizado por la École, estaba de actualidad en aquel momento 96 .

En esta investigación otorgaba al "Derecho" una preeminencia sobre los posicionamientos politicos, a los que trataba con distancia y frialdad, que contrastaba con sus politicamente significados estudios sobre partidos. Aquí, Ostrogorski consideraba al Derecho como a un "árbitro" frente al desconcierto proveniente de la politica:

"Del ruido confuso de miles de voces que resuenan en el campo cerrado de la política no sería fácil extraer la verdadera respuesta; nos arriesgaríamos gravemente a no tomar más que la voz que en cada momento domina a las otras. Pero, frente a la arena política, en la que tiene lugar la lucha de tendencias diversas que buscan imponerse a la sociedad, hay un árbitro del campo bien situado para ver las cosas. Se trata del Derecho"97.

En este punto, Ostrogorski participaba de esa visión que, despolitizando los pronunciamientos del derecho y sus especialistas, descalificaba correlativamente las posiciones de los legos, incapaces de tener una comprensión equilibrada del

93 Estas palabras se recogen en el prefacio de los editores de la traducción inglesa: Moisei Ostrogorski, The Rights of Women. A Comparative Study in History and Legislation, Swan Sonnenschein y Charles Scribner's Sons, Londres y Nueva York, 1893, p. vii.

94 Las referencias se encuentran dispersas por muchos trabajos de distinto tipo que suelen coincidir en recurrir al libro de Ostrogorski como buena fuente de información legislativa. Entre ellas: Paul Bottenheim, "Communication d'une étude sur les droits politiques des femmes aux Pays-Bas, en Danemark et dans les pays scandinaves", Bulletin de la Société de législation comparée, 2, 1913, pp. 135-186; André Lebon, "Bibliographie. La femme au point de vue du droit public", Revue Internationale de l'Enseignement, vol. 21, 1891, pp. 578-580; William E. Lecky Democracy and Liberty. Volume II, Longmans, Nueva York, 1896, pp. 529-555; Gabriel Monod, "Chronique et bibliographie", Revue Historique, vol. 49, mayo-agosto, 1892, p. 249; H. Pascaud, "Les droits électoraux des femmes dans le monde civilisé", Séances et travaux de l'Académie des sciences morales et politiques, vol. 141, 1894, pp. 740-784; Adolfo Posada, Feminismo, Librería de Fernando Fé, Madrid, 1899, pp. 158, 184.

95 Entre aquellos a los que agradecia el intercambio de documentación jurídica destacaban algunos de los juristas que luego reseñaría en los Annales, como el suizo Hilty, el polaco afincado en Austria Ludwig Gumplowicz y el belga Maurice Vauthier. El premio le permitió publicar la obra primero en francés y posteriormente traducirla al inglés (1893), al alemán (1894) y al polaco (1894). Sobre estas traducciones y sus reediciones: Igor V. Andrev, M.Ya. Ostrogorskiy: zhizn' $i$ trudy osnovopolozhnika sovremennoy partologii, op. cit., p. 71.

96 En realidad, era una cuestión de interés desde la década anterior.

97 Moisei Ostrogorski, La femme au point de vue du droit public. Étude d'histoire et de législation comparée, op. cit., p. vii. 
necesario equilibro del orden social en cada momento histórico ${ }^{98}$. En ese sentido, la observación del ordenamiento jurídico valdría, también, como herramienta para un conocimiento positivo de la evolución social:

“[E1 Derecho] bajo su triple cara de legislación, jurisprudencia y doctrina, asiste al combate y marca los golpes, pero solo anota aquellos que importan. [...] Interrogando al derecho de los diversos países sobre la condición de las mujeres desde el punto de vista del ejercicio de los derechos políticos y públicos, podemos, por tanto, comprender las fases que el movimiento en favor de los derechos de las mujeres ha recorrido en las diferentes latitudes, y darnos cuenta de los límites que la conciencia del mundo civilizado les ha asignado provisionalmente" 99 .

Aunque en el resto de sus trabajos, Ostrogorski no se significase por una comprensión naturalista del derecho, lo cierto es que solía posicionarse en favor de cualquier avance de los derechos de los individuos. Sin embargo, en este caso se mostraba especialmente explícito en su consideración de la superioridad del derecho positivo sobre el natural:

\begin{abstract}
"por muy glorioso que haya sido el rol del derecho natural como arma de combate contra la tiranía [...], no representa en realidad más que una teoría que tiene su fundamento en la metafísica y no en el derecho; porque no deriva en ningún caso de la experiencia y no expresa tampoco la relación necesaria de las cosas"100.
\end{abstract}

Este entendimiento del derecho tenía su correlato en un posicionamiento muy concreto respecto de la situación jurídica de las mujeres: los derechos civiles y las libertades profesionales e intelectuales, indispensables para el desarrollo de la personalidad, les debian ser reconocidas en toda su extensión, mientras que los derechos de participación politica que, en la línea del liberalismo decimonónico francés, Ostrogorski comprendia como funciones, no tenian necesariamente que correr la misma suerte. Para él, habia que preguntarse: “¿Qué enseñanzas proporcionan los hechos? [...] El legislador se niega obstinadamente a conceder los derechos políticos a las mujeres". Ante los comentarios críticos a su trabajo desde ambos lados de la lucha política, Ostrogorski afirmaba: "Como jurista, yo habria cometido un abuso de poder tomando partido a favor o en contra del sufragio de las mujeres, habría forzado la autoridad del derecho haciéndole intervenir en una disputa política partidista". Lo cierto es que su aceptación de la situación existente en los distintos países, aunque revestida del poder simbólico del derecho entendido como expresión de un necesario orden social, implicaba un posicionamiento respecto de la cuestión: "Mi tarea y mi deber consistirian precisamente en demostrar que el derecho de las mujeres al sufragio, que su admisión o exclusión del electorado político, lejos de responder a un principio jurídico general, era una cuestión de legislación"101.

98 Pierre Bourdieu, "La force du droit. Éléments pour une sociologie du champ juridique", Actes de la recherche en sciences sociales, vol. 64, 1, 1986, pp. 3-19.

99 Moisei Ostrogorski, La femme au point de vue du droit public. Étude d'histoire et de législation comparée, op. cit., p. vii.

100 Extraído de un artículo posterior que contenía el original francés, algo modificado, de unas nuevas conclusiones para la traducción inglesa de su libro. Moisei Ostrogorski, "Les droits des femmes", Annales de l'École libre des sciences politiques, vol. 9, 1894, p. 62.

101 Ibid., p. 63. 
No debe extrañar, por tanto, que una autora sufragista como Caroline A. Foley afirmase con ironía que con el trabajo de Ostrogorski se entraba "en el aire tranquilo del escrutinio objetivo" y apuntase a la posible incongruencia entre la defensa de un reconocimiento de la emancipación económica e intelectual de las mujeres mientras que se negaba que la concesión de los derechos politicos fuese ningún prerrequisito para la integridad de la personalidad humana ${ }^{102}$. Tampoco debe extrañar que la obra fuese acogida favorablemente en una revista juridica escocesa, basándose en que el autor se había "autolimitado, presentando una clara e interesante imagen de la posición actualmente asignada a las mujeres en el derecho público del mundo civilizado"103. Aplausos -de aquellos partidarios de una ciencia objetiva- y reproches- de aquellos inmersos en las luchas politicas-, inversos a los que recibiría su gran obra sobre los partidos.

En todo caso, no puede ignorarse que Ostrogorski aprovecharía la oportunidad para redimirse de la frialdad con la que había tratado a un movimiento, el de la extensión de los derechos políticos de las mujeres, con el que su marco ideológico y moral parecía converger. En su trabajo sobre las organizaciones de partido, el autor se mostró contrario a la posición subordinada que las mujeres ocupaban en su seno, valoró positivamente el asociacionismo político femenino en el liberalismo inglés por los principios en los que se sustentaba y por su labor de educación cívica ${ }^{104}$, y tildó de viejos prejuicios los posicionamientos contrarios al ejercicio de las funciones públicas y la participación política de las mujeres. Así, podría tratarse de una evolución en la comprensión que Ostrogorski tenía de la naturaleza de la relación entre su trabajo científico y los conflictos políticos, en la que, sin renunciar al proyecto cientificista, abria la puerta al compromiso con algunas luchas políticas. Pero también podríamos encontrarnos ante una explicación más prosaica: el pensador ruso preparó su libro sobre los derechos de las mujeres para presentarlo al Prix Rossi de la Facultad de Derecho de París, lo que pudo impulsarle a adoptar una mirada y un tono afín a los del jurado que finalmente le premió económica y reputacionalmente. Aunque seguramente se tratase de una mezcla de ambos elementos junto con un acercamiento a los argumentos expresados por el movimiento sufragista.

Este recurso al prestigio simbólico que le otorgaba su condición de experto en derecho público no se agotó en su libro de 1892, sino que tuvo sus ecos explícitos, como vimos, durante sus años de actividad política en Rusia. Por ejemplo, en 1905, en su artículo "El Manifiesto del 17 de Octubre y la Asamblea Constituyente", Ostrogorski se dirigia al lector kadet desde su condición de "constitucionalista", para caracterizar el manifiesto zarista como el acta de defunción del poder autocrático e ilimitado en Rusia y como la primera página de una constitución rusa, cuya continuación -el desarrollo jurídico de los principios enunciados- le correspondería redactar a la Duma. Correlativa a su confianza en el manifiesto y en la Duma, era su rechazo a los llamamientos de sectores

102 Caroline A. Foley, "Ostrogorski, M., The Rights of Women. A Comparative Study in History and Legislation", The Economic Journal, vol. 4, 1894, p. 93.

103 William Campbell, "Reviews of Books. La femme au Point de vue du Droit Public", Juridical Review, vol. 4, 1892, p. 77.

104 Moisei Ostrogorski, La démocratie et l'organisation des partis politiques. Vol. I, op. cit., pp. 495-524. 
importantes de la oposición a la convocatoria de una Asamblea Constituyente, lo que, en su opinión, habria espoleado a las fuerzas reaccionarias y amenazado con la vuelta a la autocracia ${ }^{105}$.

\subsection{Elementos jurídicos para la comprensión de las organizaciones de partido.}

La atención de Ostrogorski a las cuestiones jurídicas no era inusual ni acotada a los estudios referidos en el apartado anterior, sino que atravesaba también sus trabajos más explícitamente politológicos sobre los partidos, a pesar de que su método, como expuse, estuviese construido como un negativo del de los juristas. En ese sentido, el contraste permanente que Ostrogorski establecía entre los textos legales, por un lado, y la realidad politica, por otro, además de mostrar su manejo de los primeros, destilaba una relativa sacralización de estos, que solian aparecer como un referente ideal, como aspiración truncada por la perniciosa influencia de las organizaciones de partido. En varios pasajes de su libro, el autor ruso se mostraba como un profundo conocedor de leyes de distinto tipo, como aquellas que impulsaron en la Inglaterra de la primera mitad del siglo XIX el avance del individualismo (Reform Act de 1832, la emancipación de los católicos de 1829, la reforma municipal de 1835 o la derogación de las Corn Laws en 1846). No se le escapaba tampoco la complejidad de las cuestiones técnicas de las distintas leyes electorales inglesas a propósito del registro electoral o de las diferencias entre boroughs y counties, cuestiones de las que daba detenida cuenta. Igualmente, respecto de los Estados Unidos, Ostrogorski explicaba, entre otros, el contenido de la ley de 1883 de admisión al servicio federal por vía de concurso ${ }^{106}$.

Respecto del derecho inglés, Ostrogorski se posicionaba criticamente frente a la cultura jurídica del common law a propósito de sus negativos efectos sobre el desarrollo de las organizaciones partidistas. En este punto se alejaba de la opinión mayoritaria en la ELSP, institución en la que el common law se contraponía con la vocación codificadora francesa para criticar a esta última. En este alejamiento de Ostrogorski respecto de la École, seguramente debió jugar un papel su país de origen, Rusia, donde la legislación no había experimentado un proceso claro de modernización y sistematización. Para el pensador ruso, "ese método fragmentario de legislación que está en los hábitos ingleses" habría provocado dificultades en la reforma democrática del gobierno local emprendida a partir de 1832 debido a "la multiplicidad y la variedad de los organismos electivos introducidos en el self-government uno tras otro, sin ningún plan y fuera de cualquier concepción unitaria"107. En similares términos se pronunciaba respecto de la regulación del registro electoral cuya complejidad habría favorecido la extensión de la actividad del caucus en contenciosos sobre el registro de los electores:

105 Moisei Ostrogorski, "Manifest 17 oktyabrya i Uchreditel'noye sobraniye”, op. cit. Me baso en la información sobre este artículo contenida en Igor V. Andrev, M.Ya. Ostrogorskiy: zhizn' $i$ trudy osnovopolozhnika sovremennoy partologii, op. cit., pp. 109-111.

106 Moisei Ostrogorski, La démocratie et l'organisation des partis politiques. Vol. I, op. cit., pp. 3940, 336-348; La démocratie et l'organisation des partis politiques. Vol. II, op. cit., pp. 461-468.

107 Moisei Ostrogorski, La démocratie et l'organisation des partis politiques. Vol. I, op. cit., p. 47. 
"Las disposiciones legislativas sobre la materia están contenidas en más de cien textos, a los cuales hace falta todavía añadir los comentarios de una jurisprudencia que se encuentra entre las más vastas y las más confusas. [...] Siguiendo el método habitual de la legislación inglesa, que no crea todas las piezas, que no hace tabla rasa respecto de lo viejo, sino que retoca o añade, cada nueva Reform Bill que extendía el sufragio instituía un nuevo grupo de electores con condiciones particulares del censo" 108 .

En otro orden de cosas, a pesar de que, para Ostrogorski, existía una preeminencia explicativa de las fuerzas sobre las formas, esto no significaba que el derecho y las instituciones fuesen un mero producto de la acción de las organizaciones de partido y de otros actores. Revelador de esto último era el rol que otorgaba a las garantías de la Constitución de los Estados Unidos, en concreto a los derechos individuales y a la división territorial del poder, en la limitación de los efectos nocivos de los partidos. Estas habrían impedido que el boss, autócrata sobre algunas esferas limitadas, se hubiese convertido en un tirano nacional ${ }^{109}$. Igualmente, uno de los grandes objetivos de su obra era pronunciarse sobre los inflamados debates en torno a las posibles reformas de la representación que se daban en Francia. Ostrogorski desarrolló unos análisis bidireccionales en los que los partidos interesaban como fuerzas que transformaban profundamente la naturaleza de la representación política, al mismo tiempo que las reformas legales de la relación representativa podian afectar también a la naturaleza de los partidos. En sus primeros artículos sobre los partidos estadounidenses, el pensador ruso ya se había ocupado de las posibles reformas jurídicas para acabar con los males del caucus system: elección directa del presidente, creación de pequeñas circunscripciones, representación de minorias o restricciones del sufragio ${ }^{110}$. Poco después, en una reseña al trabajo de Hilty sobre el sistema constitucional suizo, Ostrogorski alertaba contra la introducción del referéndum, la iniciativa legislativa popular o la elección directa del poder ejecutivo, como vías que otorgarian excesivo poder a los políticos profesionales, acercándoles al modelo norteamericano ${ }^{111}$.

En su libro de 1903, los debates sobre la representación estaban muy presentes. Si algunos tenían un tinte, podría decirse, más teórico-político (sobre la deliberación o el fomento de la capacidad cívica entre los ciudadanos), otros eran más claramente jurídico-constitucionales. Entre estos últimos se encontraban, en primer lugar, las cuestiones sobre la extensión del sufragio, ante las cuales Ostrogorski se mostraba en desacuerdo con el ritmo a veces apresurado en la inclusión de electores que todavía estarian en la "infancia

108 Ibid., p. 345. Este rechazo explícito a las maneras del derecho inglés había tenido su antecedente más discreto en un examen de la École sobre las distintas regulaciones jurídicas de la capacidad de la mujer casada, cuando señalaba cómo el anclaje tradicional e histórico del common law, habría dificultado el avance de los derechos en este campo. Épreuves écrites. Les principaux systèmes des législations étrangères sur la capacité de la femme mariée, comparés entre eux et avec le code civil français. "Dossier d'élève de Moisei Ostrogorski”, Mission Archives.

109 Moisei Ostrogorski, La démocratie et l'organisation des partis politiques. Vol. II, op. cit., pp. 558-560.

110 Moisei Ostrogorski, "De l'organisation des partis politiques aux États-Unis (4)”, op. cit., pp. 12-30.

111 Moisei Ostrogorski, "Compte rendu de "Das politisches Jahrbuch der Sweizerischen Eidgenossenschaft", Dr. C. Hilty”, op. cit., pp. 546-549. 
política" como en su opinión, habria ocurrido con la Reform Act inglesa de 1867 o con el reconocimiento del sufragio "a la masa ignorante y embrutecida de negros liberados" en el sur de los Estados Unidos tras el final de la Guerra Civil112. A esta prevención ante la democracia ligada a la cantidad de electores, se sumaba otra ligada a la cantidad de elecciones, ya que, desde su perspectiva, un error nuclear de la teoría democrática que sustentaba argumentativamente a las organizaciones de partido era convertir al principio electivo en axioma de la libertad, o sea, considerar que siempre un mayor número de elecciones trae consigo un fortalecimiento de la soberanía de los individuos. Según Ostrogorski, este principio habría terminado por confundir a los ciudadanos ante una masa de procesos electorales (constitucionales y partidistas, es decir, elecciones corrientes y primarias) que disminuian su influencia efectiva, por lo que proponía limitar el principio electivo al poder legislativo y al gobierno local, además de alargar el tiempo de los mandatos y establecer renovaciones parciales de las cámaras ${ }^{113}$.

En segundo lugar, Ostrogorski presentaba su posición ante el problema del mandato y del control sobre el representante electo. En el análisis que llevaba a cabo de la evolución de los partidos en Inglaterra, esta cuestión era uno de los ejes principales. La teoría del caucus de Birmingham, que habia servido como ejemplo para el resto del país, descansaba principalmente sobre la idea de mandato imperativo que se entendia como intrínseco al régimen democrático. Lo que se decidía en cada escalón de la estructura del partido era vinculante para el representante, hasta llegar al diputado que también tenía un compromiso sustantivo con su partido. Si bien Ostrogorski no rechazaba por principio la mayor influencia de la opinión pública sobre el representante, sí que lo hacía cuando esta tenía un carácter mecánico y centralizado, como sería el caso del control por parte del caucus, que habría acabado con la necesaria división del trabajo entre la opinión, encargada de señalar los problemas políticos, y los gobernantes, encargados de apropiarse de aquellos cuya solución es factible y necesaria. Este equilibrio quedaba truncado toda vez que aquellos que estaban detrás de las decisiones de los diputados -ahora simples delegados- eran los líderes del caucus, situados en la sombra e irresponsables frente a los ciudadanos. Con el objeto de restituir a la opinión pública un verdadero control sobre los representantes, el pensador ruso proponía sustituir el dominio del partido sobre ellos por una posibilidad excepcional de revocación a iniciativa de los electores ante incumplimientos flagrantes del programa electoral ${ }^{114}$.

Un tercer campo jurídico-constitucional sobre el que recaía su atención el autor ruso, era el de dos reformas de la representación que en ocasiones iban de la mano: la representación proporcional y la representación de intereses. Ostrogorski era un buen conocedor de los argumentos de fondo presentados a favor de la representación proporcional en el debate inglés por parte, principalmente, de Thomas Hare y John Stuart Mill, así como de las distintas

112 Moisei Ostrogorski, La démocratie et l'organisation des partis politiques. Vol. I, op. cit., p. 544. Moisei Ostrogorski, La démocratie et l'organisation des partis politiques. Vol. II, op. cit., pp. 113, 701.

113 Ibid., pp. 571-573, 581-582, 667.

114 Moisei Ostrogorski, La démocratie et l'organisation des partis politiques. Vol. I, op. cit., pp. 150-152, 194-202, 283, 460-467, 567-574; La démocratie et l'organisation des partis politiques. Vol. II, op. cit., pp. 667-668. 
propuestas de ese tipo que se daban en Francia y otros países: escrutinio de lista, voto acumulativo, voto limitado, etc. Muy crítico con los sistemas mayoritarios que favorecian el bipartidismo, Ostrogorski encontraba atractiva la representación proporcional como vía de expresión para las minorías políticas, aunque también insuficiente en un contexto dominado por los partidos ${ }^{115}$. Menos adecuadas consideraba las propuestas para "organizar" el sufragio, encuadrarlo en un marco colectivo o grupal y no individual, es decir, la denominada como representación orgánica o de intereses, que ocupaba de forma intensa a los iuspublicistas franceses, quienes encontraban en los debates constitucionales belgas de finales de siglo un buen fondo de armario de experiencias y argumentos. Su oposición a estas propuestas se desprendía de manera natural de los valores individualistas que sustentaban su pensamiento. A pesar de este rechazo general, Ostrogorski proponía una pequeña representación de grupos (cámaras de comercio, sindicatos, sociedades de conocimiento, profesores o iglesias) en la cámara alta, pero lo hacia en tanto que estos portaban un conocimiento especializado sobre cuestiones legislativas, no porque representasen ningún interés particular ${ }^{116}$.

En general, el hábil manejo de material y de conceptos jurídicos y constitucionales contrastaba con la comprensión del derecho en ocasiones algo precaria que tenían aquellos profesores de la École sin formación como juristas. En ese sentido, Boutmy, a pesar de sus valiosos trabajos de historia constitucional, llegó a afirmar que la diferencia entre el derecho público y el privado radicaba en que el primero no tenía una sanción cierta, algo dificilmente sostenible a finales del siglo $\mathrm{XIX}^{117}$. Tal enredo traía causa del conflicto institucional de la École con las facultades ${ }^{118}$, lo que, eximiendo en cierta manera al director de la institución, no deja de apuntar a una losa de prejuicios disciplinares en los que el autor ruso, ajeno a estas polémicas entre instituciones, no tenía tanta inclinación en caer. En realidad, no había contradicción entre, por un lado, las críticas de Ostrogorski al enfoque jurídico y su adscripción a la ciencia política en el libro de 1903 y, por otro lado, su autocomprensión como "constitucionalista" o "especialista en derecho público" y sus aportaciones como jurista a las que me vengo refiriendo. La separación entre ambos campos era aún difusa y, además, el pensador ruso podía considerar, como de hecho muchos de sus contemporáneos lo hacían, que uno podía ser jurista sin comulgar con una comprensión sellada a influencias externas a la disciplina.

Lo que se acaba de enunciar puede parecer evidente para cualquiera sensible a los problemas intrínsecos a la proyección sobre el pasado de las categorias del presente, en este caso de las etiquetas disciplinares. Sin embargo, a propósito de

115 Moisei Ostrogorski, La démocratie et l'organisation des partis politiques. Vol. I, op. cit., pp. 95106; La démocratie et l'organisation des partis politiques. Vol. II, op. cit., pp. 658-664.

116 Ibid., pp. 538-542, 653-657. Ostrogorski consideraba que la mejor defensa de la representación de intereses se encontraba en los trabajos del jurista belga Adolphe Prins, La démocratie et le régime parlementaire, Muquardt, Guillaumin, Bruselas, París, 1884; L'organisation de la liberté et le devoir social, Muquart, Falk, Alcan, Bruselas, París, 1895.

117 Émile Boutmy, Des rapports et des limites des études juridiques et des études politiques, Armand Colin, Paris, 1889, p. 16.

118 Pedro L. López Herraiz, Formar al hombre de Estado. Génesis y genealogía de la École libre des sciences politiques, op. cit., pp. 189-222." 
Ostrogorski es importante subrayarlo toda vez que, desde mediados del siglo XX y hasta hoy, varios campeones de la ciencia politica moderna han venido excluyendo o ignorando esta traza jurídico-constitucional de sus estudios. En 1955, Gabriel Almond y algunos de sus colegas buscaban exportar la formalizada y cuantitativa ciencia politica norteamericana a una Europa occidental que se habría quedado anclada en los enfoques históricos, legal-analíticos y filosóficos, con un objetivo político explícito: aportar herramientas intelectuales para frenar la extensión del comunismo en países como Francia o Italia ${ }^{119}$. Ostrogorski era, para Almond, un ejemplo de esa beneficiosa ciencia política que, aun sin apartar la dimensión histórica, adoptaba una perspectiva sociológica. Se ignoraba, así que, el autor ruso encajaba también en los otros dos rasgos denostados de la ciencia politica continental (sus intereses jurídicos y filosóficos). Poco tiempo después, Lipset y George Catlin insistirian en cómo la intención de Ostrogorski de centrarse en las "fuerzas" habia supuesto su alejamiento respecto del legal government y su consecuente concentración en los aspectos sociológicos ${ }^{120}$. Más adelante, en el artículo que inauguró en 1995 la revista Party Politics, Richard Katz y Peter Mair repetirian, esta vez desde una perspectiva crítica, la misma idea. Ambos estasiólogos condenaban la línea inaugurada por nuestro autor de considerar a los partidos principalmente "sobre la base de su relación con la sociedad civil", lo que había determinado unas tipologías y análisis errados, y una infravaloración de la "extensión con la cual las diferencias entre partidos deben ser entendidas también en referencia a sus relaciones con el Estado". De nuevo se caía en el error de considerar que la obra de Ostrogosrki era ciega a los elementos institucionales"121. En fin, en un extravagante "Family Tree of Comparative Politics", el importante estudioso de las transiciones a la democracia, Philippe Schmitter, situaba recientemente a Ostrogorski junto a Michels y Weber en una de las dos grandes ramas, la del estudio de la sociedad politica inaugurada por Aristóteles, mientras que la otra rama, centrada en las instituciones y fundada por Platón, tenía entre sus continuadores a contemporáneos del ruso como Lowell, Bryce, Léon Duguit o Woodrow Wilson ${ }^{122}$.

Seguramente lo que vienen a mostrar indirectamente estas incautas lecturas politológicas de Ostrogorski como ajeno a los elementos institucionales que se relacionan con los partidos es la necesidad de integrar estos para una explicación más completa del fenómeno partidista. Una realidad como la de los partidos, hoy claramente situada a medio camino entre el Estado, para el que cumplen

119 Gabriel A. Almond, Taylor Cole, Roy C. Macridis, "A Suggested Research Strategy in Western European Government and Politics", The American Political Science Review, vol. 49, 4, 1955, pp. 1043-1046.

120 George E. Catlin, Systematic politics. Elementa politica et sociologica, Toronto University Press, Toronto, 1965, p. 263; Seymour M. Lipset, "Introduction. Ostrogorski and the Analytical Approach to the Comparative Study of Political Parties", op. cit., pp.xv-xvi.

121 Richard S. Katz, Peter Mair, "Changing Models of Party Organization and Party Democracy: The Emergence of the Cartel Party", Party Politics, vol. 1, 1, 1995, pp. 5-6. De hecho, en una crítica inmediata al texto de Katz y Mair se discutía su originalidad, apuntando que la relación entre el Estado y los partidos ya había sido expuesta por otros autores, entre ellos Ostrogorski, que se habria referido al spoils system y al patronazgo. Ruud Koole, "Cadre, Catch-all or Cartel? A Comment on the Notion of the Cartel Party", Party Politics, vol. 2, 4, 1996, pp. 515-516

122 Philippe C. Schmitter, "The nature and future of comparative politics", European Political Science Review, vol. 1, 1, 2009, pp. 36-39. 
importantes funciones tanto en su seno como fuera de él, y la sociedad, de la que extraen sus apoyos, sus integrantes y su dirección política, no puede ser abordada desde la ignorancia ni de lo social ni de lo jurídico. Es cierto que un enfoque holístico que tuviese en cuenta todos los factores que afectan al desarrollo de los partidos es dificilmente compatible con la inevitable especialización a las que se ve abocada la ciencia social actual. Lo que Ostrogorski, con todas las limitaciones y los prejuicios de su tiempo, trató de llevar a cabo -un estudio sociológico, histórico, constitucional y filosófico de las organizaciones de partido- no encaja en las coordenadas de nuestra práctica científica. Si Ostrogorski subrayó el elemento sociológico en su investigación es porque este era el más ignorado en un momento en el que, además, los partidos eran antes una realidad social que jurídica. Hoy son ambas cosas y, por ello, los juristas llevan décadas estudiando los partidos. Aunque, también hoy, las fronteras disciplinares entre el derecho público y la ciencia politica son más infranqueables que lo que eran entonces, dificultando una interlocución disciplinar especialmente necesaria respecto de los partidos. Veamos ahora cómo los juristas franceses contemporáneos al pensador ruso leyeron -o no- una obra respecto de la cual alguno de ellos sí percibió esa traza constitucional ignorada por la ciencia política posterior.

\subsection{El moment 1900 de la ciencia juridica francesa desde la perspectiva de sus lecturas de Ostrogorski.}

La larga estancia de Ostrogorski en Francia coincidió con un periodo especialmente fructífero de la ciencia jurídica francesa, el conocido como moment 1900, que podriamos situar entre 1880 y el comienzo de la Gran Guerra. Como ha sido señalado por Fréderic Audren, este momento no es, a diferencia de lo que ha sido sostenido por las interpretaciones clásicas iniciadas en las décadas de 1920 y 1930, una "edad de oro" de la doctrina francesa representada de forma excelente y univoca en las figuras de Carré de Malberg, Duguit, Esmein, Maurice Hauriou o Raymond Saleilles ${ }^{123}$. O, al menos, no es solo eso. Frente a esta lectura retrospectiva con tintes de celebración nacional, corre otro análisis más riguroso que subraya el contexto de crisis disciplinar permanente en el que se incardinaban estos juristas. No se trataria, como normalmente se ha pensado, de una ciencia jurídica encerrada sobre sí misma para la construcción de una dogmática aséptica, sino más bien de un campo plural, atravesado por los problemas politicos de su tiempo y por otras disciplinas emergentes con las que discutía y de las que se enriquecía, como la sociología, la ciencia política, la historia o la psicología. Atender a cómo los juristas de este moment 1900 se relacionaron con la obra de Ostrogorski nos habla de la naturaleza heterogénea de este espacio disciplinar

Si bien es cierto que Ostrogorski no realizó ninguna crítica explícita y directa a los juristas franceses de su tiempo, tampoco ofreció muestras de valorar su trabajo, cuyos intereses, en algunos casos no le quedaban demasiado lejos ni en lo temático ni en lo metodológico. Un caso interesante es el de la relativa

123 Frédéric Audren, "Le "moment 1900" dans l'histoire de la science juridique française", en Olivier Jouanjan, Élisabeth Zoller (eds.), Le "moment 1900" des doctrines et pratiques juridiques, Éditions Panthéon-Assas, París, 2015, pp. 55-74. 
ignorancia mutua entre el autor ruso y dos grandes representantes del derecho público francés de principios del siglo $\mathrm{XX}$ abiertos a cuestiones políticas $\mathrm{y}$ sociales, Hauriou y Duguit ${ }^{124}$. Si la ausencia de referencias de Ostrogorski a los maestros de Toulouse y Burdeos se explica seguramente por cuestiones cronológicas, ya que estos no escribieron sus grandes tratados hasta poco después de la publicación de su libro de 1903, la práctica inexistencia de referencias por parte de estos iuspublicistas a la obra de Ostrogorski tiene más que ver con la naturaleza de sus trabajos. Usando los términos del ruso, se puede afirmar que a ambos les interesaban antes las formas que las fuerzas, y aunque sus reflexiones sobre la representación, la soberanía y el poder alcanzasen un elevado nivel teórico, ignoraban casi por completo el eventual rol que los partidos podian jugar en la vida política de estos conceptos.

De hecho, si ambos citaban superficialmente a Ostrogorski era, probablemente, porque habían conocido su obra a partir del extenso comentario que otro de sus ilustres colegas, Esmein, hizo en la Revue politique et parlementaire ${ }^{125}$. No debe extrañar que fuese este profesor de derecho constitucional de la Facultad de París y de la ELSP el que, desde el campo de los juristas, prestase más atención a la obra de Ostrogorski. Más allá de su compartido rechazo a la idea de mandato imperativo, introducida por las organizaciones de partido ${ }^{126}$, Esmein era, entre los grandes juristas de ese moment 1900, el más abierto a tres elementos que estaban presentes en la obra de Ostrogorski y, en general, en el planteamiento de la École, institución en la que no llegaron a coincidir: cuestiones politicas, método comparativo y enfoque histórico. En realidad, más que abierto a ellos, eran parte intrínseca de su acercamiento al derecho constitucional. A partir de la quinta edición de sus influyentes Éléments de droit constitutionnel français et comparé (1909), Esmein recurrió al trabajo de el autor ruso para acercarse al efecto de los partidos sobre el régimen parlamentario en Inglaterra, afirmando que:

"Un publicista de gran talento, M. Ostrogorski, ha expuesto en una gran obra el procedimiento de los partidos. Condena su formación y su organización, que ha estudiado mejor que nadie antes, no solo en Inglaterra sino también en los Estados Unidos [...]. M. Ostrogorski no se contenta con poner al desnudo los males demasiado reales y demasiado numerosos que trae consigo la

124 Sobre la relevancia de ambos en la construcción doctrinal del estado republicano francés: Jean-Michel Blanquer, Marc Milet, L'Invention de l'État: Léon Duguit, Maurice Hauriou et la naissance du droit public moderne, Odile Jacob, París, 2015.

125 Citando a Ostrogorski, Hauriou tocaba superficialmente la cuestión de las organizaciones de partido al tratar sobre el "poder del sufragio": Maurice Hauriou, Précis de droit constitutionnel, Sirey, París, $2^{a}$ ed., 1929, pp. 545-546. Por su parte, Duguit en ninguno de los cinco tomos de su tratado prestaba una atención detenida a los partidos políticos y se limitaba a mentar la obra de Ostrogorski a propósito de su crítica al mandato imperativo, en la que coincidian: Léon Duguit, Traité de droit constitutionnel. Tome 2. La théorie générale de l'État. Elements, fonctions et organes de l'État, E. de Boccard, Paris, 3a ed., 1928, p. 656. Ambos acompañaban la cita de Ostrogorski del artículo sobre su obra de Esmein, lo que invita a pensar que fue a través de su colega francés como conocieron la obra del publicista ruso: Adhémar Esmein, "La démocratie et l'organisation des partis politiques de M. Ostrogorski”, Revue politique et parlementaire, vol. 37, julio-septiembre, 1903, pp. 117-133, 358-368.

126 Didier Mineur, "Les partis politiques et la logique philosophico-juridique de la représentation politique”, Raisons politiques, vol. 20, 4, 2005, pp. 89-109. 
organización de los partidos [...]. Presenta también un plan de reforma, un modelo de Constitución para los países libres"127.

Más allá de su atención a la problemática de los partidos (en cuya valoración difería respecto del pensador ruso al considerarlos necesarios para la articulación de la democracia), a Esmein le interesaban especialmente las propuestas de reforma de la representación y de las vías para articular esta última, las ligas. Como lector atento, Esmein supo ver que esta obra iba más allá de un simple trabajo de observación de una realidad politica y que su valor radicaba también en su incursión en el campo de la discusión constitucional. Este jurista avistó también las debilidades que en ese campo presentaban los planteamientos de Ostrogorski, discutiendo varias de sus propuestas, entre ellas, principalmente, la de sustituir a los partidos por ligas, ya que le parecia "reposar sobre una idea un poco vaga de los procedimientos necesarios de la legislación"128.

Joseph Barthélemy, futuro ministro de Justicia de la Francia de Vichy, profesor de derecho constitucional en la Facultad de Derecho de París y de historia parlamentaria y legislativa en la ELSP, realizó el prefacio y revisó la sexta edición de los Éléments de Esmein en 1914. El carácter de la relación entre la obra de ambos va más allá de los propósitos de este artículo, pero si en algo coincidian era en su atención al funcionamiento y a la historia de las instituciones políticas, incluso más acentuado en el caso de Barthélemy, lo que, evidentemente, incluía a los partidos políticos. Además de en otros trabajos ${ }^{129}$, Barthélemy se refería críticamente al rol de las organizaciones de partido en un libro de 1907 sobre el poder ejecutivo en perspectiva comparada, en el que Ostrogorski aparecía como referencia a propósito de la dependencia del presidente de los Estados Unidos respecto de la machine ${ }^{130}$. Barthélemy pretendió sumarse con su Traité du droit constitutionnel de 1926 a esa lista de los grandes arquitectos de la reflexión constitucional francesa de la época-Carré de Malberg, Duguit, Esmein y Hauriou-, pero el carácter teoréticamente débil de su trabajo, más atento a la historia política que a la dogmática constitucional, le convirtió en el antecedente temprano de un estudio del derecho constitucional entendido como historia comparada de las instituciones que eclosionaria tras la Segunda Guerra Mundial con las figuras de Georges Burdeau y Maurice Duverger ${ }^{131}$. En coordenadas ideológicas similares a las de Barthélemy se movía otro profesor de la ELSP, Charles Benoist: republicano conservador, atemorizado ante el avance del socialismo en el sistema parlamentario de la III República que también

127 Adhémar Esmein, Éléments de droit constitutionnel français et comparé, Sirey, 5a ed., 1909, pp. 198-199.

128 Adhémar Esmein, "La démocratie et l'organisation des partis politiques de M. Ostrogorski", op. cit., p. 363

129 Joseph Barthélemy, Démocratie et politique étrangère. Cours professé à l'École des HautesÉtudes sociales en 1915-1916, Félix Alcan, París, 1917; Le pròblème de la compétence dans la démocratie. Cours professé à l'École des Hautes-Études sociales pendant l'année 1916-1917, Felix Alcan, Paris, 1918.

130 Joseph Barthélemy, Le rôle du pouvoir exécutif dans les républiques modernes, Giard et Brière, París, 1906, pp. 122-123, 233. Aparecían también citados autores con las mismas preocupaciones temáticas como Bryce o Lowell.

131 Olivier Beaud, "Joseph Barthélemy ou la fin de la doctrine constitutionnelle classique", Droits, vol. 32, 2000, pp. 89-108. 
evolucionaria hacia posiciones reaccionarias. Antes político y publicista que jurista, el itinerario intelectual de Benoist estuvo marcado por la lectura de Ostrogorski132.

Se podría seguir atendiendo a estas recepciones del trabajo del pensador ruso entre los juristas franceses, pero lo dicho hasta ahora ya apunta a dos cuestiones interesantes. La primera de ellas es conocida y el caso de Ostrogorski no es más que un pequeño ingrediente del relato historiográfico: el moment 1900 de la ciencia jurídica francesa no era monolitico y estaba marcado por las temáticas políticas y por el diálogo interdisciplinar. En ese sentido, el contraste entre la atención de Esmein, Barthélemy o Benoist, y la inadvertencia de Duguit o Hauriou -por no hablar del caso de Carré de Malberg133-, expresa nítidamente estas diferencias entre autores, en ocasiones encuadrados con una excesiva pretensión de homogeneidad. La segunda de ellas, inevitablemente, es menos conocida: la obra de Ostrogorski no era exclusivamente un trabajo de ciencia política, sino también de teoría constitucional.

No obstante, más allá de esta panorámica de los estudios jurídicos franceses del cambio de siglo, que La démocratie et l'organisation des partis politiques se situase explicitamente en el campo de la ciencia política ha tenido y tiene como consecuencia un marcado contraste entre el número de lecturas por parte de los politólogos, muy abundante, y de los juristas, bastante escaso. Que los partidos no fuesen objeto de regulación o reconocimiento jurídico y constitucional hasta bien entrado el siglo XX colaboró en la relativa ceguera de los juristas frente al emergente fenómeno. Una excepción evidente y ya clásica fue la del intenso debate que tuvo lugar durante la República de Weimar en torno al concepto de Parteienstaat o Estado de Partidos, en un contexto en el que en Europa continental los partidos de masas fuertemente organizados fuera del parlamento ocuparon un importante lugar dentro de él134. Hans Kelsen, en directa polémica con juristas conservadores como Carl Schmitt o Triepel, acompañó su defensa del parlamentarismo de una defensa de los partidos politicos, considerando que estos últimos eran una condición necesaria para el funcionamiento de la democracia ${ }^{135}$. Que Kelsen no recurriese a la obra de Ostrogorski para defender sus posiciones y que, sin embargo, sí que lo hiciese Schmitt ${ }^{136}$, vuelve a mostrar

132 Charles Benoist, "Le suffrage universel et l'évolution des partis politiques", op. cit.; pp, 520542. "Comment on capte le suffrage et le pouvoir. La "machine", op. cit; pp. 885-918. Gaetano Quagliariello, Politics Without Parties. Moisei Ostrogorski and the Debate on Political Parties on the Eve of the Twentieth Century, op. cit., pp. 180-189.

133 Representante del positivismo estatalista, estaba en las antípodas de las claves temáticas y metodológicas de Ostrogorski. Sobre su obra: Didier Mineur, Carré de Malberg. Le positivisme impossible, Michalon, París, 2010.

134 Un debate mas complejo de lo que aquí se puede enunciar y que ha sido influyente en la dogmática constitucional española. Dos buenas introducciones son: Roberto L. Blanco Valdés, Los partidos políticos, Tecnos, Madrid, 1990, pp. 47-54; Manuel García Pelayo, "El Estado de Partidos", en Obras completas, vol. 2, Centro de Estudios Constitucionales, Madrid, 1991, pp. 1983-1990.

135 Hans Kelsen, De la esencia y valor de la democracia, Juan Luis Requejo Pagés (trad.), KRK Ediciones, Oviedo, 2006 [1929], pp. 71-73.

136 Carl Schmitt, The Crisis of Parliamentary Democracy, Ellen Kennedy (trad.), The MIT Press, Cambridge (MA) y Londres, 1985 [1926], p. 20. 
de nuevo a qué perfil de juristas les podía resultar más sugerente la obra del autor ruso: a aquellos más alejados de una ciencia jurídica purgada de otras influencias disciplinares.

En un momento crítico para la propia existencia de las organizaciones de partido y de la democracia en general, Kelsen propuso una solución que se generalizó en la segunda mitad del siglo XX y que integraría definitivamente a los partidos en las reflexiones de los juristas: su constitucionalización. El triunfo moral de los partidos antifascistas en la Segunda Guerra Mundial conllevó, a través del reconocimiento de los partidos en las nuevas constituciones (como la italiana de 1947 o la Ley Fundamental de Bonn de 1949), su consideración jurídica definitiva como instrumentos de participación y representación política llamados a realizar funciones centrales del estado democrático. Un camino que sería continuado en las décadas siguientes por prácticamente todos los países europeos, entre ellos Francia en 1958 y España en 1978137. En nuestro país, con ocasión del proceso constituyente abierto en 1977, tuvo lugar un encuentro académico en la Universidad de Salamanca sobre la constitucionalización de los partidos que, más allá de la incidencia que pudiese tener en el debate constitucional, resulta significativo porque en él coincidieron varios académicos que, por aquel momento, se situaban bajo el paraguas del "derecho político" y que, posteriormente, emprenderian la ruptura disciplinar entre el derecho constitucional y la ciencia política que en otras latitudes ya se había producido décadas antes ${ }^{138}$. Varios de los trabajos aquí recogidos, que asumian diversos enfoques (dogmática constitucional, historia, filosofia política, derecho comparado o ciencia politica), daban cuenta de la obra de Ostrogorski, por aquel momento ya clásica, y extendían un importante campo de estudio en la ciencia política y el derecho constitucional españoles ${ }^{139}$. De nuevo, este caso nos habla del interés que un trabajo como el del autor ruso puede tener para perspectivas diversas.

137 Ingrid Van Biezen, "Constitutionalizing Party Democracy: The Constitutive Codification of Political Parties in Post-war Europe”, British Journal of Political Science, vol. 42, 1, 2012, pp. 187212.

138 Entre los constitucionalistas, encontramos nombres como los del coordinador de la publicación Pedro de Vega, o los de Pedro Cruz Villalón, Francisco Rubio Llorente, Luis Sánchez Agesta, Eliseo Aja y Pablo Lucas Verdú, entre muchos otros. Entre aquellos que impulsarian el desarrollo de los estudios de partidos desde una perspectiva politológica, destacan José Ramón Montero y Ramón Cotarelo. Pedro de Vega (ed.), Teoría y práctica de los partidos politicos, Cuadernos para el Diálogo, Madrid, 1977.

139 Aunque no debe ignorarse que desde distintas perspectivas el pensamiento sobre partidos en España viene dándose desde el siglo XVIII, como ha sido claramente expuesto en Ignacio Fernández Sarasola, Los partidos políticos en el pensamiento español. De la Ilustración a nuestros dias, Marcial Pons, Madrid, 2009. Desde la perspectiva de los constitucionalistas españoles de las últimas décadas, ha destacado la atención dedicada a la problemática de la democracia interna de los partidos, lo que se explica por tratarse justamente de una cuestión que ha sido objeto de regulación constitucional. Manuel Contreras, Carlos Garrido, Interiores del príncipe moderno. La democracia en los partidos, entre la necesidad y la dificultad, Comuniter, Zaragoza, 2015; Fernando Flores Giménez, La democracia interna de los partidos politicos, Publicaciones del Congreso de los Diputados, Madrid, 1998; José Navarro Hernández, Partidos politicos y "democracia interna", Centro de Estudios Políticos y Constitucionales, Madrid, 1999; Miguel A. Presno Linera, Los partidos políticos y las distorsiones jurídicas de la democracia, Ariel, Barcelona, 2000. 


\section{CONCLUSIONES.}

Lo que se desprende principalmente de este artículo es una crítica, apoyada en distintos elementos biográficos e intelectuales, de la lectura de Ostrogorski como padre de la ciencia política empírica. Esta lectura genealógica llevada a cabo por la ciencia política de la segunda posguerra, siendo, desde mi perspectiva, equivocada, tiene su explicación. Ostrogorski formaba parte de un movimiento académico politológico que pretendió, a finales del siglo XIX, superar las limitaciones de una ciencia jurídica que había sido incapaz de dar cuenta del emergente fenómeno de los partidos de masas (apartado III.1). En ese marco, propuso y practicó un estudio de las fuerzas -los partidos- por encima de las formas -las instituciones-, atento al funcionamiento "extra-constitucional" del gobierno (III.2).

Sin embargo, esa lectura politológica es discutible por distintas vías. Este trabajo ha explorado una de las principales: su relación con el mundo del derecho y su incontestable condición, no solo de científico político, sino también de jurista. La propia biografia del autor ruso nos muestra nítidamente esta última faceta. Ostrogorski se formó en distintas materias jurídicas tanto en Rusia como en Francia, ejerció importantes cargos como alto funcionario del Ministerio de Justicia en el Imperio Ruso y aplicó todos estos conocimientos y experiencias en su corta pero intensa labor como diputado en la primera Duma (II). En una obra algo olvidada, La femme au point de vue du droit public (1892), Ostrogorski asumió una comprensión del "Derecho" como "árbitro" de las situaciones políticas y como vía para un conocimiento del necesario orden social y de su punto de equilibro evolutivo. De esta manera, Ostrogorski se emparentaba con las corrientes positivistas de una manera dificilmente integrable con los planteamientos que después desarrollaria en sus estudios sobre partidos (IV.1). Estos últimos estudios, por los que se le considera fundador de la ciencia politica alejada de los elementos institucionales, están repletos, no obstante, de consideraciones juridicas. El autor ruso se mostraba en ellos como buen conocedor de distintas leyes y debates constitucionales, principalmente a propósito de la relación representativa, y asumía una postura ante ellos y ante la cultura jurídica del common law (IV.2). Si quedaba alguna duda de su incardinación en el mundo jurídico de su tiempo, basta atender a la lectura que de su obra hizo un importante iuspublicista, Esmein, quien supo ver el fondo de discusión constitucional que contenía su estudio de las organizaciones de partido (IV.3).

Entre las conclusiones secundarias de este trabajo, una de ellas proviene de la atención a las lecturas de Ostrogorski por parte de los juristas del moment 1900, más allá de la figura Esmein. El distinto grado de atención de los Barthélemy, Benoist, Carré de Malbert, Duguit o Hauriou, viene a mostrar desde un ángulo nuevo, una realidad ya conocida: que ese fructífero periodo de la ciencia jurídica no era en absoluto uniforme, ni consistía simplemente en la construcción de la gran dogmática del derecho público, sino que estaba marcada por los conflictos politicos y por su relación con otras ciencias sociales (IV.3).

En ese contexto de reordenación disciplinar del cambio de siglo, tratar de situar a un trabajo con tantas aristas como el de Ostrogorski de manera unívoca en un campo acotado es una tarea inadecuada. Más aún cuando esto se trata de hacer, como se ha hecho por parte de Lipset y otros científicos políticos, 
trasladando etiquetas disciplinares del presente a un pasado que se movía con otras. Mostrando esto para nuestro caso concreto, se corrobora la artificialidad de las fronteras disciplinares y se discute la idea -aún no enterrada- de que la división actual en las ciencias sociales es el producto de una evolución natural y necesaria. A medio camino entre el derecho, la historia, la filosofia y la ciencia política, la obra de Ostrogorski muestra cómo, en otros momentos históricos, otras combinaciones disciplinares fueron posibles.

Por último, pueden enunciarse otras dos conclusiones laterales más directamente dirigidas a la figura del pensador ruso. En primer lugar, sin pretender reconstruir una imposible coherencia entre su visión del derecho en su trabajo sobre los derechos de las mujeres de 1892 y su planteamiento politológico de 1903, hay un hilo que conecta ambas obras. Se trata de la confianza en la ciencia positiva, en el conocimiento extraído de una observación rigurosa de la realidad, ya fuese esta jurídica o política, para pacificar los conflictos presentes en las sociedades. Asumiendo que la siguiente categorización es ficticia, podría decirse que tanto el Ostrogorski jurista como el Ostrogorski científico politico recurrian al poder simbólico del conocimiento científico para trasladar al debate público su particular posicionamiento frente a cuestiones como el avance de los derechos politicos de las mujeres o de los partidos de masas (III.2 y IV.1). En segundo lugar, si se rescatan varios de los elementos biográficos y de las motivaciones de los trabajos de Ostrogorski aquí presentados, puede afirmarse que, a nivel académico, este pensador nacido en el Imperio Ruso era principalmente francés (II y III.1). Aunque esta última afirmación es lo suficientemente polémica respecto de la literatura existente sobre su figura como para requerir de un mayor desarrollo que presentaré en otros trabajos.

Fecha de envío / Submission date: 13/03/2019

Fecha de aceptación / Acceptance date: 23/04/2019 